\title{
Structural and functional magnetic resonance imaging of autism spectrum disorders
}

\author{
Kimberly A. Stiglera,b, ${ }^{a}$, Brenna C. McDonald ${ }^{c}$, Amit Anand $^{\mathrm{b}, c}$, Andrew J. Saykinc ${ }^{\mathrm{c}}$, and \\ Christopher J. McDougle ${ }^{a, b}$ \\ ${ }^{a}$ Christian Sarkine Autism Treatment Center, James Whitcomb Riley Hospital for Children, \\ Indianapolis, IN, USA \\ bDepartment of Psychiatry, Indiana University School of Medicine, Indianapolis, IN, USA \\ 'Department of Radiology, Indiana University School of Medicine, Indianapolis, IN, USA
}

\begin{abstract}
The neurobiology of autism spectrum disorders (ASDs) has become increasingly understood since the advent of magnetic resonance imaging (MRI). Initial observations of an above-average head circumference were supported by structural MRI studies that found evidence of increased total brain volume and early rapid brain overgrowth in affected individuals. Subsequent research revealed consistent abnormalities in cortical gray and white matter volume in ASDs. The structural integrity and orientation of white matter have been further elucidated via diffusion tensor imaging methods. The emergence of functional MRI techniques led to an enhanced understanding of the neural circuitry of ASDs, demonstrating areas of dysfunctional cortical activation and atypical cortical specialization. These studies have provided evidence of underconnectivity in distributed cortical networks integral to the core impairments associated with ASDs. Abnormalities in the default-mode network during the resting state have also been identified. Overall, structural and functional MRI research has generated important insights into the neurobiology of ASDs. Additional research is needed to further delineate the underlying brain basis of this constellation of disorders.
\end{abstract}

\section{Keywords}

Autism; Autism spectrum disorder; Magnetic resonance imaging; Neurobiology; Review

\section{Introduction}

Autistic disorder (autism) and related pervasive developmental disorders (PDDs) are profound neuropsychiatric conditions characterized by impairments in social skills and communication, as well as repetitive interests and activities. The most commonly diagnosed PDDs, autism, Asperger's disorder, and PDD not otherwise specified (NOS), are often referred to as autism spectrum disorders (ASDs). Epidemiological research suggests that ASDs affect at least 60 per 10,000 youth, with estimates as high as 100 per 10,000 (BaronCohen et al., 2009; Fernell and Gillberg, 2010). In addition, ASDs are considered highly heritable polygenetic disorders, with concordance rates for autism in monozygotic twins ranging from $60 \%$ to greater than $90 \%$ (Bailey et al., 1995; Ritvo et al., 1985).

\footnotetext{
(C) 2010 Elsevier B.V. All rights reserved

${ }^{*}$ Corresponding author: Department of Psychiatry, James Whitcomb Riley Hospital for Children, 702 Barnhill Drive, Rm. 4300, Indianapolis, IN 46202-5200, USA. Fax: +1 317948 0609. kstigler@iupui.edu (K.A. Stigler)..
} 
In 1943, Leo Kanner first described autism in a case report of 11 patients who had a "fundamental inability to relate themselves in the ordinary way to people and situations from the beginning of life." In this landmark work, Kanner provided an enduring characterization of autism that is closely reflected in the current criteria of the Diagnostic and Statistical Manual of Mental Disorders (Fourth Edition, Text Revision) (DSM-IV-TR) (American Psychiatric Association, 2000). This description included symptoms of autistic aloneness, echolalia, pronoun reversal, and need for sameness, among others. Of importance, Kanner believed that autism was congenital in nature and astutely noted the presence of "relatively large heads" in five of the eleven children in his case report; a key observation that would later be supported by research into the neurobiological underpinnings of autism.

In light of Kanner's (1943) original observation that some patients with autism had enlarged heads, researchers began investigations of head circumference as a means to determine whether individuals with autism are macrocephalic (head size greater than two standard deviations above the mean). The findings from these studies, which included both children and adults, revealed that approximately $15 \%-20 \%$ of subjects with autism exhibited macrocephaly (Aylward et al., 2002; Bailey et al., 1993; Fombonne, 2000; Lainhart et al., 1997, 2006). However, it was difficult to meaningfully interpret these results because head circumference is considered to provide a fairly accurate indication of brain size in early childhood, but not in adolescence or adulthood (Bartholomeusz et al., 2002).

Recognizing that autism first emerges early in life, investigators studied head circumference in infants who later developed autism. As a whole, head circumference in this group was found to be average or slightly below average at birth (Courchesne et al., 2003; Dawson et al., 2007; Dementieva et al., 2005; Hazlett et al., 2005; Lainhart et al., 1997). However, brain growth was then found to accelerate on or before 1 year of age, with $15 \%-20 \%$ developing macrocephaly by $4-5$ years of age.

These intriguing findings compelled researchers to further explore the brains of individuals with autism in an in vivo fashion and on a larger scale than could be done before. Early studies employed computerized tomography (CT), an imaging modality that used ionizing radiation, to ascertain neuroanatomy. Although gross abnormalities were initially found, many subjects suffered from other potential causes of brain damage (e.g., infectious, genetic, neurologic) that likely confounded the results (Damasio et al., 1980). Subsequent CT studies used rigorous screening procedures to enroll subjects with idiopathic autism (Campbell et al., 1982; Rosenbloom et al., 1984). Overall, these studies did not show significant gross anatomical abnormalities and supported Kemper and Bauman's (1998) hypothesis of an aberrant neuropathology at the microscopic level in the autistic brain. Taken together, these early studies only modestly contributed to the knowledge base in autism. Ultimately, CT was found to have concerning limitations such as poor spatial resolution and use of ionizing radiation that greatly restricted its use. New imaging technologies would clearly be needed to advance the understanding of brain structure and function in individuals with ASDs.

In fact, a new technology was evolving from two seminal studies of nuclear magnetic resonance conducted in 1946 (Huettel et al., 2009). By the 1970s, research advances in the area had led to the first biological images captured by magnetic resonance imaging (MRI) techniques. Magnetic resonance imaging has a high degree of spatial resolution and contrast sensitivity, as well as an absence of ionizing radiation. However, it was not until the 1980s that the clinical use of structural (s) MRI for brain imaging became widespread. Diffusion tensor imaging (DTI), a MRI technique for assessing white matter microstructure in the brain, underwent investigation during the 1980s (Pierpaoli et al., 1996; Taber et al., 2002). In the 1990s, researchers found that changes in blood oxygenation could be measured in the brain using functional (f) MRI. The advent of these novel neuroimaging techniques using 
MRI would soon herald a new era of investigation into the neuroanatomy and neurocircuitry of ASDs.

This review provides a synopsis of relevant sMRI and fMRI studies in ASDs to date, with an emphasis on well-designed, controlled research. Structural MRI findings that are summarized include studies of total brain volume (TBV) and specific neuroanatomic structures, as well as DTI. Functional MRI results, encompassing task-based, as well as resting state studies of the default-mode network (DMN), are subsequently reviewed.

\section{Results}

\subsection{Structural magnetic resonance imaging}

2.1.1. Total brain volume-In light of prior research suggesting early abnormal brain enlargement, investigators launched sMRI studies in an effort to better delineate brain abnormalities in ASDs. Although autism had been considered a static process, new insights gleaned from head circumference data suggested a dynamic process of age-dependent brain growth abnormalities. To further explore this possibility, Courchesne et al. (2001) conducted a sMRI study that quantified developmental abnormalities in TBV in boys with autism. Of the autism group, half was scanned at 2-4years of age, whereas the other half was scanned at 5-16 years of age. Review of neonatal head circumference records suggested that TBVs were normal for the children with autism at birth. However, by 2-4 years of age, $90 \%$ of the autism group had larger mean TBVs than the controls, and 37\% met criteria for macrocephaly (Fig. 1). The young autism group also exhibited more cerebral (18\%) and cerebellar (39\%) white matter, as well as more cerebral cortical (12\%) gray matter than normal. In contrast to these findings, the older autism group (5-16 years) did not have larger mean TBVs than the older control group.

An increase in TBV has been consistently reported in young children with autism, with some studies suggesting a 5\%-10\% enlargement (Carper et al., 2002; Courchesne et al., 2001; Hazlett et al., 2005; Sparks et al., 2002; Stanfield et al., 2008). A meta-analysis of available data from head circumference, postmortem, and sMRI studies of children with autism revealed a pattern of dysregulated brain growth (Redcay and Courchesne, 2005). Individuals exhibited reduced or normal brain size at birth, underwent rapid brain overgrowth during early childhood, and then experienced a plateau in brain growth such that brain size was within the normal range by adolescence and adulthood (Fig. 2)(Courchesne et al., 2007). However, other researchers have documented persistent brain enlargement in adolescents and adults with autism (Freitag et al., 2009; Hazlett et al., 2006).

2.1.2. Gray and white matter contributions-The finding of early brain enlargement in children with autism intrigued researchers who in seeking a more detailed understanding determined that brain volume did not change in a uniform manner. Both gray and white matter abnormalities have been identified throughout the brain, reflecting the distributed nature of brain involvement in ASDs (Carper et al., 2002; Muller, 2008). Among the various reported abnormalities, increased frontal lobe volume has emerged as one of the most consistent findings (Brun et al., 2009; Carper et al., 2002; Hazlett et al., 2006; Herbert et al., 2004; Palmen et al., 2005). Research has demonstrated increases in volume of dorsolateral prefrontal (DLPFC) (Mitchell et al., 2009), as well as DLPFC and medial prefrontal cortex (MPFC) (Carper and Courchesne, 2005; Herbert et al., 2004). Other findings suggest that there may be no difference or even a decrease in orbitofrontal cortex (OFC) volume in ASDs (Girgis et al., 2007; Hardan et al., 2006a).

Regional differences in gray matter volume have been documented throughout the brain but particularly in areas of the frontal cortex (Hardan et al., 2006b) such as middle frontal gyrus, 
superior frontal gyrus, inferior frontal gyrus (IFG), and medial OFC, among others (Bonilha et al., 2008; Hadjikhani et al., 2006; Hardan et al., 2009a; Hyde et al., 2010; McAlonan et al., 2005; Waiter et al., 2004). Volumetric differences of gray matter have also been found along the superior temporal sulcus (STS), inferior parietal lobule, cingulate, and fusiform gyrus (FG), among others (Boddaert et al., 2004; Bonilha et al., 2008; Hadjikhani et al., 2006; McAlonan et al., 2005; Rojas et al., 2006; Waiter et al., 2004).

Regional differences in white matter volume have also been found in several brain regions such as cerebellum and corpus callosum, with abnormalities mostly observed in outer radiate compartments (Amaral et al., 2008; Carper and Courchesne, 2005; Herbert et al., 2004; Stanfield et al., 2008). This was demonstrated by Herbert et al. (2004) in their study of boys with autism and controls (half with typical development and half with developmental language disorder). Although increased volume was found in the outer zone of radiate white matter in all lobes in the autism group, a clear predominance was noted in the frontal lobe. In contrast, no volume differences were recorded in the inner zone of white matter (i.e., corpus callosum, internal capsule). The authors suggested that these results indicated brain overgrowth of short- and medium-range intra-hemispheric corticocortical connections and a lack of involvement of inter-hemispheric corticocortical connections in autism.

Additional characteristics of cortex, such as shape and thickness have also been investigated in ASDs. Abnormalities in cortical shape have been identified in the sylvian fissure, STS, intraparietal sulcus, right parietal lobe, and IFG (Kates et al., 2009; Levitt et al., 2003; Nordahl et al., 2007). Recently, abnormalities in cortical folding were found in the frontal lobe of boys with autism, but not Asperger's disorder (Jou et al., 2010). Of note, the left inferior frontal region (e.g., Broca's area) exhibited the most prominent increase in gyrification.

Research regarding cortical thickness has also been conducted. A study of children with autism versus typically-developing controls found increased total cerebral sulcal and gyral thickness, largely due to increases in temporal and parietal lobes (Hardan et al., 2006c). Another study of cortical thickness was conducted in adults with ASDs and healthy comparison subjects, finding cortical thinning in frontal, parietal, and temporal regions in the ASD group (Hadjikhani et al., 2006). Hardan et al. (2009a) conducted a preliminary longitudinal study of TBV and cortical thickness in children with autism versus typicallydeveloping controls. Although no difference was found in TBV between groups, greater differences in TBV were observed in the autism group over time in several regions, including the frontal lobe. Recently, investigators used cortical thickness analysis and voxelbased morphometry in a study of young adults with autism and healthy controls (Hyde et al., 2010). Both techniques found structural alterations (primarily gray matter increases) in regions of the brain implicated in social and communication impairment, and repetitive behavior.

2.1.3. Cerebellum—Although the cerebellum has historically been considered to be involved in motor coordination, it also has been shown to have a role in modulating emotion, language, and executive function (Hodge et al., 2010). Volumetric studies of the cerebellum in ASDs have included the vermis and total cerebellum. Research findings regarding the vermis have greatly varied. Although an early study published by Courchesne et al. (1988) found decreases in cerebellar vermal lobules VI and VII in comparison to healthy controls, this finding was not replicated in several subsequent studies (Garber and Ritvo, 1992; Hashimoto et al., 1992; Holttum et al., 1992; Kleiman et al., 1992; Piven et al., 1992). Due to these inconsistent findings, Courchesne et al. (1994) conducted a larger study assessing vermal lobules VI and VII. Two subgroups were found; one large subgroup (86\%) with hypoplasia and one small subgroup (14\%) with hyperplasia of the region. Subsequent 
research documented decreases in vermal lobules VI and VII (Akshoomoff et al., 2004; Kaufmann et al., 2003). Recently, a meta-analysis also demonstrated decreased size of vermal lobules VI and VII in younger individuals with autism (Stanfield et al., 2008). In contrast to the vermis, studies of total cerebellum have generally found increased volumes in children with ASDs (Hardan et al., 2001b; Herbert et al., 2003; Palmen et al., 2005; Sparks et al., 2002).

2.1.4. Amygdala-The amygdala plays an important role in emotional and social behavior (Adolphs, 2008). Similar to other sMRI findings in ASDs, volumetric research regarding the amygdala has also been inconsistent, with age emerging as a significant factor. Amygdala volume has been found to be increased in children with autism less than ten years of age versus typically-developing controls (Schumann et al., 2004; Schumann et al., 2009). Bilateral amygdala enlargement was found in children with autism aged 3-4 years versus typically-developing controls, and right amygdala volume was positively correlated with social and communication impairment (Munson et al., 2006; Sparks et al., 2002). More recently, bilateral enlargement of the amygdala was reported in children with autism aged 15 years in comparison to typically-developing controls, with a positive correlation between amygdala volume and social and communication impairment found in the autism group (Schumann et al., 2009).

In contrast, research that has included adolescent or adult subjects with autism reported either no difference (Haznedar et al., 2000) or smaller amygdala volumes versus healthy controls (Aylward et al., 1999; Nacewicz et al., 2006; Pierce et al., 2001). Interestingly, the study by Nacewicz et al. (2006) found that decreased amygdala volume was associated with decreased time fixating on the eye region of faces. This led investigators to hypothesize that the age-related trajectory of amygdala growth may be similar to that of early brain overgrowth in young children with autism (Courchesne et al., 2007).

2.1.5. Hippocampus-The hippocampus is critically involved in associative memory and the integration of information. Volumetric studies of the hippocampus in autism versus healthy controls have revealed divergent findings. Several studies have noted no difference in hippocampal volume (Bigler et al., 2003; Haznedar et al., 2000; Howard et al., 2000; Piven et al., 1998; Saitoh et al., 1995). However, other researchers have reported decreased or increased hippocampal volume (Aylward et al., 1999; Nicolson et al., 2006; Schumann et al., 2004; Sparks et al., 2002). Subject heterogeneity and varied imaging methodologies may have contributed to these inconsistencies.

2.1.6. Insula-The anterior insula functions to integrate multiple neurocognitive systems associated with affective, empathic, and interoceptive processes (Kosaka et al., 2010; Menon and Uddin, 2010; Uddin and Menon, 2009). As such, it may play an important role in the neurobiology of ASDs. Recently, decreased gray matter was documented in the right insula and IFG in adults with ASDs versus healthy controls (Kosaka et al., 2010).

2.1.7. Fusiform gyrus-The FG, specifically the fusiform face area (FFA), is implicated in aspects of face processing that involve face identification (Haxby et al., 2002). Volumetric studies of the FG have found unchanged, increased, or decreased volumes in adolescents and adults with ASDs versus healthy controls (Pierce et al., 2001; Toal et al., 2010; Waiter et al., 2004). In addition, asymmetries of the FG were reported in boys with autism in comparison to typically-developing healthy controls (Herbert et al., 2002).

2.1.8. Superior temporal sulcus-The cortex along the banks of the superior temporal sulcus (STS) has been found to play a role in processing eye movements (Hoffman and 
Haxby, 2000; Puce et al., 1998). The region is involved in the interpretation of dynamic social cues (e.g., direction of eye gaze, gestures, facial expressions) (Allison et al., 2000; Pelphrey et al., 2005). Research has found anterior and superior displacements, as well as decreased bilateral gray matter volumes, of the STS in youth with autism versus typicallydeveloping controls (Boddaert et al., 2004; Levitt et al., 2003).

2.1.9. Planum temporale-The left planum temporale (PT) (i.e., Wernicke's area) plays a crucial role in auditory processing and receptive language (Nakada et al., 2001). As such, it has been associated with lexical processing (Bookheimer, 2002). This region has been found to be larger on the left in children and adolescents with autism in comparison to typically-developing controls (Herbert et al., 2002). However, reduced left PT volume was reported in a study of children, as well as in a study of adults, with autism versus healthy controls (Rojas et al., 2002; Rojas et al., 2005). Recently, Knaus et al. (2009) conducted a study of children and adolescents with ASD, dividing them up into a 7-11 year-old group and a 12-19 year-old group. The authors found increased left PT volume and a stronger leftward asymmetry in the older group in comparison to typically-developing controls.

2.1.10. Inferior frontal gyrus-The left IFG (i.e., Broca's area) is important in sentence comprehension, integrating areas involved in syntactic and semantic processing, as well as working memory (Bookheimer, 2002). Abell et al. (1999), in a sMRI study of adults with autism, reported decreased volume in this region. Rightward asymmetry of the IFG was reported in children with autism (Herbert et al., 2002). This asymmetry reversal was also noted in a study of boys with ASDs (De Fosse et al., 2004). However, the finding only occurred in the presence of language impairment.

2.1.11. Caudate-The caudate, a part of the basal ganglia that subserves executive function, has been implicated in the development of stereotyped and repetitive behaviors (Turner et al., 2006). Several studies have found an increase in caudate volume, as well as a positive correlation between caudate volume and repetitive behavior, in youth and adults with autism (Brambilla et al., 2003; Hollander et al., 2005; Rojas et al., 2006). Sears et al. (1999) also reported an increase in caudate volume in adolescents and adults with autism. However, predominantly negative correlations were found between caudate volume and repetitive behavior. Changes in caudate volume were examined in a study of children and adults with ASDs versus healthy controls, noting an increase in volume with development (Langen et al., 2007). A negative association was found between caudate volume and repetitive behavior in the autism group. A volumetric study that focused not on repetitive behavior, but executive function, documented larger caudate volumes in children with ASDs compared to typically-developing and bipolar disorder controls (Voelbel et al., 2006). A positive correlation was found between caudate volume and impaired problem solving.

2.1.12. Thalamus-The thalamus is involved in multiple roles encompassing language and emotion processing, as well as components of executive function (Katz and Shatz, 1996). Several sMRI studies that included a wide age range of individuals with ASDs have not found significant structural abnormalities in the thalamus (Hardan et al., 2006a; Haznedar et al., 2006; Tsatsanis et al., 2003). However, Hardan et al. (2008) conducted a study of children with autism that revealed a positive correlation between thalamic volume and TBV in both the autism and typically-developing control group.

2.1.13. Cingulate cortex-Neurons originating within the cingulate cortex are the first to cross the midline during development (Korkmaz et al., 2006). This region has reciprocal connections with nearly all areas of the cerebral cortex, as well as subcortical, brainstem, and spinal connections. Whereas the posterior cingulate cortex (PCC) is believed to play a 
role in visuospatial and memory function, the anterior cingulate cortex (ACC) primarily appears to be involved in the integration of affect, cognition, and behavioral expression. Haznedar et al. (1997) recorded significantly smaller ACC volume in adults with autism in comparison to healthy controls.

2.1.14. Corpus callosum-The corpus callosum, a white matter tract connecting the cerebral hemispheres, facilitates interhemispheric connectivity. Numerous studies have recorded deficits of corpus callosum volume in subjects with autism versus healthy controls (Chung et al., 2004; Egaas et al., 1995; Freitag et al., 2009; Hardan et al., 2000, 2009b; Keary et al., 2009; Manes et al., 1999; Piven et al., 1997; Saitoh et al., 1995; Vidal et al., 2006), whereas others have not documented significant differences (Elia et al., 2000; Gaffney and Tsai, 1987; Herbert et al., 2004; Tepest et al., 2010). A meta-analysis found reduced total corpus callosum area in subjects with autism versus healthy controls (Frazier and Hardan, 2009). The anterior regions of corpus callosum had the largest area of reduced volume.

2.1.15. Brainstem-The brainstem is involved in sensory modulation (Ornitz, 1983). Early volumetric studies found reduced brainstem volume in autism versus healthy controls (Gaffney et al., 1988; Hashimoto et al., 1995). However, other investigations demonstrated no significant differences (Elia et al., 2000; Hardan et al., 2001a; Herbert et al., 2003; Kleiman et al., 1992; Piven et al., 1992). Recently, Jou et al. (2009) documented a decrease in brainstem gray matter volume in children with autism compared to typically-developing controls. A positive correlation was found between brainstem gray matter volume and oral sensory sensitivity.

2.1.16. Diffusion tensor imaging—Research studies employing DTI in children and adults with ASDs have found decreased fractional anisotropy (coherent fiber tract directionality) in several white matter regions, such as VMPFC, OFC, ACC, external capsule, internal capsule, corpus callosum, temporal stem, ventral temporal lobe, and STS, and superior and middle cerebellar peduncles, among others (Alexander et al., 2007; BarneaGoraly et al., 2004; Bloemen et al., 2010; Brito et al., 2009; Catani et al., 2008; Cheung et al., 2009; Keller et al., 2007; Lee et al., 2007; Pardini et al., 2009; Pugliese et al., 2009; Thakkar et al., 2008).

2.1.17. Summary-Taken together, structural neuroimaging research has made valuable contributions to our understanding of the neuro-anatomy of ASDs. Investigators have demonstrated increased TBV and early rapid brain overgrowth, as well as decreased white matter integrity in several brain regions. However, inconsistencies have been found in the location and direction (increase or decrease) of change in brain volume, as well as in the contribution of gray and white matter (Amaral et al., 2008; Bonilha et al., 2008; Stanfield et al., 2008). The diverse findings have been hypothesized to be due to the heterogeneity of ASDs, as well as differences in diagnostic criteria, subject characteristics [e.g., age, intelligence quotient (IQ), gender], and imaging methodologies (Amaral et al., 2008; Craig et al., 2007; Kwon et al., 2004; McAlonan et al., 2008; Stanfield et al., 2008).

\subsection{Functional magnetic resonance imaging}

\subsubsection{Task-based studies of core symptoms}

2.2.1.1. Social cognition: A significant portion of fMRI research in ASDs has focused on delineating the neurobiology of core social impairment. Face perception, a central aspect of social cognition, is one of the earliest emerging social deficits in ASDs (Dawson et al., 2005). Research has found differences in the way individuals with ASDs visually scan faces. Whereas typically-developing controls rely on the eye region and use a holistic-style when 
processing faces, subjects with ASDs tend to focus more on the mouth region and use a feature-based style (Klin et al., 2002; Pelphrey et al., 2002; Weeks and Hobson, 1987).

2.2.1.1.1. Neutral face tasks: Given that face perception is considered an essential component of social cognition, investigators began to conduct fMRI studies that employed emotionally neutral face tasks (Hubl et al., 2003; Pierce et al., 2001; Schultz et al., 2000). In these studies, individuals with ASDs demonstrated either no activation or lower activation in the FFA in response to the tasks. The ASD subjects tended to exhibit greater activation in more object-related brain regions. A more recent fMRI study of adults with autism versus healthy controls found decreased activation in the FFA, occipital face area, and STS (Humphreys et al., 2008).

In contrast to these findings, Hadjikhani et al. (2004) reported significant activation in the FFA in adults with ASDs and healthy controls. However, in this study, subjects were cued to attend to the eye region via a central fixation cross. This suggested that FFA activation may be related to the degree of gaze fixation. Another study also found significant activation in the FFA in response to a neutral face task in adults with ASDs and healthy controls (Kleinhans et al., 2008b). In the ASD group, increased social impairment was associated with decreased FFA-amygdala connectivity and increased FFA-right inferior frontal connectivity (Fig. 3). A subsequent fMRI study assessed changes in amygdala and FFA in response to neutral face stimuli in adults with ASDs versus healthy controls (Kleinhans et al., 2009). In comparison to the ASD group, the controls exhibited significantly greater bilateral amygdala habituation. Overall, no differences were recorded in fusiform habituation between groups. The authors concluded that individuals with ASDs may experience amygdala hyperarousal in response to socially relevant stimuli.

2.2.1.1.2. Familiar face tasks: Pierce et al. (2004) conducted a fMRI study of adults with autism and healthy controls using a familiar face task. Significant activation in the FFA in response to familiar and stranger faces was found in both groups. The authors hypothesized that the inclusion of almost a dozen familiar faces for each subject may have enhanced attention and motivation in the subjects with autism throughout the entire task. Another fMRI study using a familiar face task was conducted in children with ASDs versus typically-developing controls (Pierce and Redcay, 2008). Subjects with autism demonstrated normal FFA activity in response to a familiar face (their mother) or another child's face. In contrast, significant deficits in FFA activity were observed in response to adult faces of strangers in comparison to controls, suggesting reduced attention during this condition.

2.2.1.1.3. Emotional face tasks: Other researchers have utilized emotional face tasks in fMRI studies of individuals with ASDs. Critchley et al. (2000) examined brain activation in adults with autism versus healthy controls during an emotional face task. In comparison to the control group, the autism group did not activate a cortical 'face area' when explicitly assessing emotions or the left amygdala and left cerebellum when implicitly processing facial emotions. An investigation of children and adolescents with ASDs versus typicallydeveloping controls revealed no differences in activation when labeling facial emotions (cognitive task) (Wang et al., 2004). However, the ASD group demonstrated decreased FFA activation in comparison to controls when matching facial expressions, an automatic process. Decreased FFA activation in response to matching facial emotions was found in a study of children and adolescents with ASDs versus typically-developing controls (Piggot et al., 2004). No differences in task accuracy were found between groups.

Another study found that adolescents and young adults with autism versus healthy controls exhibited activation in the FFA and amygdala that was positively correlated with time spent fixating on the eyes during an emotional face task (Dalton et al., 2005). The authors 
suggested that a heightened emotional response may be associated with gaze fixation in autism. Pelphrey et al. (2007) used a dynamic and static emotional face task in a study of adolescents and adults with autism versus healthy controls. The authors observed reduced activity in the amygdala and FG to dynamic emotional expressions in the autism group.

Recently, a study of children with autism versus typically-developing controls found decreased activation of the FFA and amygdala while matching facial emotions, even though task performance was intact (Corbett et al., 2009). While matching people, the autism group exhibited deficits in task performance associated with some FFA and variable amygdala activation. These findings were consistent with abnormalities in the neural circuitry involved in emotion and face processing. Kleinhans et al. (2010) found significantly greater activation in bilateral FFA, left amygdala, right pulvinar, and bilateral superior colliculi during a supraliminal fearful face task in healthy controls compared to adults with ASDs. The authors noted that the ASD group did not engage subcortical face regions involved in face detection and automatic emotional face processing. A fMRI study found increased right amygdala activation in adults with ASDs in comparison to healthy controls when attention bias to emotional faces was equivalent between groups (Monk et al., 2010).

2.2.1.1.4. Eye gaze: A fMRI study showed that brain regions involved in gaze processing, including the STS, are not sensitive to intentions conveyed by gaze shifts in adults with autism versus healthy controls (Pelphrey et al., 2005). This finding may contribute to the gaze processing deficits associated with autism.

2.2.1.1.5. Theory of mind and the mirror neuron system: Individuals with ASDs suffer from deficits in theory of mind, known as the ability to attribute mental states to oneself and others, as well to use these attributions in understanding and predicting the behavior of others (Premack and Woodruff, 1978). Neuroimaging studies have recently begun to investigate the neural basis underlying impairments in theory of mind in youth and adults with ASDs (Castelli et al., 2002; Gilbert et al., 2009; Lombardo et al., 2010; Wang et al., 2006). These studies found abnormal patterns of activation in the neural network subserving theory of mind, namely the MPFC, STS, and right temporal pole (Frith and Frith, 2003).

Deficits in theory of mind associated with ASDs may develop as a result of early mirror neuron system (MNS) dysfunction (Dapretto et al., 2006). Although the MNS has been identified in the ventral premotor and parietal cortex of the macaque, it has not been directly confirmed in humans via neuropathological studies. However, neurophysiological and neuroimaging research has contributed to the identification of a human homologue of this system in the pars opercularis of the IFG and the posterior parietal cortex. The human MNS plays a critical role in action observation and imitation, as well as in the understanding of emotions (Buxbaum et al., 2005; Cattaneo and Rizzolatti, 2009; Iacoboni et al., 1999; Johnson-Frey et al., 2003; Rizzolatti and Craighero, 2004).

A fMRI study of MNS activation in ASDs during the imitation and observation of emotional facial expressions was conducted by Dapretto et al. (2006). Although there was no difference in task performance between groups, no MNS activity was observed in the pars opercularis of the IFG in children with ASDs versus typically-developing controls. An inverse correlation was found between MNS activation and social impairment (Fig. 4). The authors concluded that a dysfunctional MNS may underlie the social deficits observed in autism. The neural underpinnings of imitation were investigated in adolescent males with ASDs and typically-developing controls (Williams et al., 2006). In comparison to the control group, the ASD group demonstrated decreased activation of the MNS in the somatosensory cortex and increased activation of the dorsal premotor and dorsal prefrontal cortex. The authors suggested that the altered connectivity patterns observed during imitation in ASDs 
could arise from deficient integration among areas subserving visual, motor, proprioceptive, and emotional functions. It was hypothesized that this could negatively affect the development of theory of mind through imitation in ASDs.

Martineau et al. (2010) published a fMRI study of adults with autism versus healthy controls. Increased activation of IFG was documented during the observation and execution of hand movements compared to a control condition (rest) in the ASD group versus controls. This finding suggests that atypical MNS activity may be central to the core social deficits of ASDs. However, another fMRI study of adults with autism versus controls found that the individuals with autism exhibited normal fMRI responses in MNS areas during the observation and execution of hand movements (Dinstein et al., 2010).

The neural mechanisms of empathy were investigated in adolescents with ASDs and their fathers, comparing them to healthy control groups (Greimel et al., 2010). During the presentation of emotional faces, subjects were asked to infer the emotional state from the face or judge their own emotional response to the face. When ASD subjects attributed emotions to self and other, decreased activation was noted in FFA compared to controls. In addition, when ASD subjects inferred their own emotional response to faces, they showed decreased activity in IFG. In part, the findings provided evidence of aberrant mirroring mechanisms associated with empathy impairments in ASDs.

2.2.1.1.6. Summary: Atypical patterns of FFA activation have consistently been found during face processing in ASDs, suggesting a critical role for this region in socioemotional functioning. Whereas many studies demonstrated decreased or absent activation, others recorded increased FFA activation during face processing. These contradictory findings may be explained by differences in gaze patterns, visual attention, and/or motivation to attend to faces in this diagnostic group (Klin and Klin, 2008; Scherf et al., 2010). Finally, recent investigations have suggested that early MNS dysfunction may play an important role in the development of theory of mind deficits in ASDs.

2.2.1.2. Language and communication: Autism spectrum disorders are associated with a wide range of language and communication impairments. Most individuals with ASDs exhibit some degree of semantic, syntactic, and pragmatic deficits (Groen et al., 2008; Harris et al., 2006). However, linguistic deficits may vary considerably, ranging from a lack of functional speech to outstanding language abilities in this diagnostic group. Studies using fMRI have recently begun to contribute to our understanding in this area, often demonstrating abnormalities in the left IFG and PT.

Just et al. (2004) utilized a sentence comprehension task to examine semantic and syntactic processing in adults with autism versus healthy controls. Increased left PT activation and decreased left IFG activation, as well as decreased connectivity, were found in the autism group (Just et al., 2004). A fMRI study of adults with ASDs and healthy controls was conducted using a single-word lexical semantic processing task (Harris et al., 2006). The study revealed less activation in left IFG but increased activation of the PT in the ASD group relative to controls. In addition, decreased differences in activation between concrete and abstract words were observed in the ASD group.

Language and working memory were investigated in a fMRI study of adults with autism versus healthy controls (Koshino et al., 2005). The investigators employed a n-back working memory task with letters to examine verbal working memory. Although task accuracy was similar between groups, the autism group exhibited decreased activation in left frontal regions reflecting a possible tendency for individuals with autism to use visual strategies during task completion. Adults with autism were compared with healthy controls during a 
fMRI study that employed a sentence processing task with high- and low-imagery content (Kana et al., 2006). Although the use of visualization is not necessary for processing lowimagery sentences, the autism group activated parietal and occipital regions of the brain associated with imagery for both the low- and high-imagery task conditions. The authors hypothesized that individuals with autism may be more dependent on visualization for language processing. Gaffrey et al. (2007) investigated changes in activation associated with a semantic category decision word task in adults with ASDs compared to healthy controls. The control group showed significant activation for semantic decision in the left IFG, whereas the autism group exhibited more limited activation in this region. In addition, significantly greater activation was recorded in bilateral extrastriate visual cortex in the autism group versus controls, suggesting an important role of perceptual components such as visual imagery in semantic processing in autism. Recently, Sahyoun et al. (2010) evaluated the networks underlying visuospatial versus linguistic (semantic) processing in children with autism and typically-developing controls via a pictorial reasoning paradigm. In contrast to the control group, the autism group activated occipito-parietal and ventral temporal areas, suggesting a dependence on visual mediation in autism.

Semantic functions were also examined in adolescents with ASDs and typically-developing controls utilizing a reading version of a response-naming task (Knaus et al., 2008). Although both groups performed the task at ceiling levels, subjects with ASDs versus controls had significantly increased activation in IFG, which was less left lateralized. In contrast to the control group, the ASD group did not demonstrate a significant correlation between IFG and PT activation in the left hemisphere. Letter and category fluency was investigated in a fMRI study of adolescents and adults with ASDs versus healthy controls (Kleinhans et al., 2008a). Letter fluency requires the use of lexical retrieval strategies, whereas category fluency relies on overlearned semantic knowledge. The ASD group exhibited significantly greater activation of the right frontal and superior temporal lobes during the letter fluency task compared to the control group. In addition, significantly reduced lateralization in activation patterns in letter fluency was observed in the subjects with ASDs versus controls. The authors hypothesized that atypical structural and functional organization may contribute to language impairment in ASDs.

Pragmatic language comprehension has been investigated in children and adults with ASDs (Mason et al., 2008; Wang et al., 2006). In these studies, subjects with ASDs versus controls exhibited increased activation of the right IFG during narrative and irony comprehension tasks. Tesink et al. (2009) also investigated pragmatic language comprehension in a study of adults with ASDs versus healthy controls. The authors examined the neural correlates of the integration of speaker characteristics inferred from the voice and content of a message.

There were no differences in task accuracy between groups. Relative to the control group, the ASD group showed increased activation in the right IFG that was likely compensatory in nature.

Redcay and Courchesne (2008) investigated the neural correlates of language development in young children with autism. A fMRI study was conducted during natural sleep as a means to identify brain regions involved in speech perception in youth with autism aged 2-3 years versus controls. In comparison to the chronological age matched controls, the ASD group demonstrated increased activation within right and medial frontal regions. In addition, the ASD group versus mental age matched controls exhibited decreased activation in a network of brain regions typically recruited during early language acquisition. Overall, the findings suggest an aberrant developmental language trajectory in young children with autism.

2.2.1.2.1. Summary: Functional MRI research has contributed to our understanding of the neurobiology of language and communication impairment in ASDs. Several studies have 
shown a pattern of decreased left IFG and increased PT activation in subjects with ASDs compared to controls. This pattern suggests an increased tendency of individuals with ASDs to engage in more extensive processing of the meanings of individual words versus integrating their meanings into a coherent conceptual structure. In addition, research supports the role of visual imagery in semantic processing in this diagnostic group. Although additional research is needed, young children with autism appear to be on an early deviant trajectory of language development.

2.2.1.3. Executive functions and repetitive symptoms: Individuals with ASDs commonly exhibit repetitive interests and activities. Some investigators have hypothesized that these repetitive symptoms may be due to deficits in executive function that impair behavioral control in this diagnostic group (Lopez et al., 2005).

Executive function subsumes several domains of cognition including inhibition, working memory, set shifting, and planning (Dichter and Belger, 2007; Russo et al., 2007).

A study of response inhibition found decreased ACC activation in adults with autism relative to healthy controls (Kana et al., 2007). In addition, decreased functional connectivity was found between the inhibition network (ACC, middle cingulate gyrus, insula) and the right middle and inferior frontal and right inferior parietal regions. These results suggest an atypical inhibition circuitry in individuals with autism. Increased rostral ACC activation was recorded during correct trials of a response monitoring task in adults with ASDs versus healthy controls (Thakkar et al., 2008). The authors suggested that individuals with ASDs may misinterpret this as a signal that something is wrong, which may trigger repetitive attempts at correction. This may contribute to the core repetitive behavior observed in ASDs.

The effects of processing directional face information on a cognitive brain network were assessed in adults with autism and healthy controls (Dichter and Belger, 2007). Whereas unimpaired activation of a cognitive control network was found while processing non-social stimuli, decreased activation in this network occurred while processing social stimuli. Thus, processing of social stimuli may interfere with cognitive control in ASDs. A subsequent study examined the effects of viewing high-arousal pictures on brain activation during a cognitive control task in adults with autism and healthy controls (Dichter and Belger, 2008). When low-arousal pictures preceded cognitive control stimuli, no differences in brain activation were found between the groups. When high-arousal pictures preceded cognitive stimuli, the control group exhibited increased right lateral midfrontal cortex activation, whereas the autism group did not modulate activity in this region. This indicated that areas of cognitive control may be abnormally sensitive to social-emotional context in ASDs.

In the aforementioned study by Koshino et al. (2005), adults with autism and controls had similar behavioral results on a verbal working memory task. Whereas the autism group employed a visually-oriented processing style, the control group used verbal strategies during task completion. Spatial working memory was investigated via an oculomotor delayed response task in a study of adults with autism and healthy controls (Luna et al., 2002). The autism group versus controls exhibited decreased task-related activation in the DLPFC and PCC. In comparison to typically-developing controls, adolescents with ASDs showed decreased activation in medial and lateral premotor cortex, DLPFC, caudate, and ACC, during a spatial working memory task (mental rotation task) (Silk et al., 2006). These results suggest that frontostriatal networks are dysfunctional in ASDs.

Another component of executive function, planning, was assessed with the Tower of London task in a fMRI study of adults with autism and healthy controls (Just et al., 2007). 
Although no significant differences in brain activation were found between groups, evidence of decreased connectivity was recorded between frontal and parietal areas in the subjects with autism. This finding suggested that a lower degree of information integration across certain cortical regions may contribute to the executive function deficits observed in autism.

2.2.1.3.1. Summary: The neural basis of executive function deficits in ASDs has been increasingly investigated via fMRI methods. Some studies of executive function have indicated a potential relationship between impaired response inhibition and repetitive symptoms in ASDs. Other research has shown that, despite similar behavioral performance on certain executive function tasks, individuals with ASDs versus controls exhibit underlying abnormalities in brain activation and connectivity. As such, this diagnostic group may employ different cognitive processes when completing these tasks.

2.2.2. Resting state connectivity and the default-mode network—Resting state studies are investigations into the functional connectivity of a brain region when the subject is not performing any coordinated, purposeful task (Huettel et al., 2009). Mental events continue to arise even during the resting state, activating the DMN. This network is a set of brain regions whose activity decreases during active, engaging tasks and increases during conditions of rest and reflection (Huettel et al., 2009). Increased activity of the DMN has also been found during tasks involving autobiographical memory, future prospection, and theory of mind (Broyd et al., 2009).

Resting state connectivity studies have found abnormalities of the DMN in autism (Cherkassky et al., 2006; Kennedy et al., 2006). Continuous resting state data assessed connectivity between three seed regions of the DMN (MPFC, PCC/precuneus, left angular gyrus) and all voxels in the brain in adolescents and adults with ASDs and healthy controls (Kennedy and Courchesne, 2008a). Decreased functional connectivity was recorded in the DMN in the autism group due to specific abnormalities of the MPFC and left angular gyrus. The DMN was investigated during social and introspective tasks, and at rest in adolescents and adults with ASDs versus healthy controls (Kennedy and Courchesne, 2008b). Decreased functional activity was found in the ventral MPFC/ACC in the ASD group across the task and rest conditions.

Intrinsic functional connectivity within the DMN was evaluated in ASDs (Monk et al., 2009). A single seed was placed in the PCC. In comparison to healthy controls, adults with ASDs demonstrated decreased connectivity between the PCC and superior frontal gyrus and increased connectivity between PCC and both right temporal lobe and right parahippocampal gyrus. In the ASD group, worse social functioning was correlated with decreased connectivity between the PCC and the superior frontal gyrus. More severe repetitive behavior was associated with increased connectivity between the PCC and right parahippocampal gyrus. Ebisch et al. (2010) investigated the intrinsic connectivity of the insula in ASDs by means of resting state fMRI. Using four seeds placed in anterior and posterior regions of insula, the autism group showed decreased connectivity of bilateral posterior insular cortices with ventral and dorsal somatosensory cortices and between anterior insular cortices (right hemisphere) and amygdala. The integrity of functional connectivity within default-mode sub-networks was assessed using brief resting fMRI scans in adults with ASDs and healthy controls (Assaf et al., 2010). The default-mode subnetworks were found to be similar between groups. However, the ASD group exhibited decreased connectivity between the precuneus and MPFC/ACC. The authors found a negative correlation between functional connectivity in these regions and severity of social and communication impairment. 
2.2.2.1. Summary: The DMN plays a putative role in self-referential mental representation and theory of mind. As such, study of the DMN may be highly relevant to ASDs. Recent investigations of this network in individuals with ASDs have revealed atypical patterns of functional connectivity. Furthermore, researchers are beginning to find correlations between the core symptom domains of ASDs and connectivity between certain regions of the DMN. Additional research is greatly needed to better understand the functional significance of the DMN in this diagnostic group.

\section{Discussion}

The concept of autism as a brain-based disorder began with a highly significant early observation, namely the finding of "relatively large heads" in some children with autism. Although this finding would later be verified via studies of head circumference, new technologies were clearly needed to further our understanding of ASDs. Several decades would pass after Kanner's original observations before investigators would begin to actively utilize MRI techniques in an effort to elucidate the neurobiological underpinnings of ASDs.

The initial findings of increased head circumference in autism were confirmed by sMRI studies that demonstrated increased TBV in affected individuals. An atypical trajectory of neurodevelopment in autism was identified that began with a period of rapid brain overgrowth in early childhood and was followed by a plateau in brain growth resulting in normal total brain volume by adolescence. Consistent abnormalities in cortical gray and white matter volume have also been identified in ASDs. Studies have found an increase in intrahemispheric white matter volume along with a decrease in interhemispheric (i.e., corpus callosum) white matter volume in autism. White matter abnormalities have been increasingly explored at a microstructural level with DTI. Investigations of neural circuitry with fMRI via task-based and resting state approaches have demonstrated abnormalities in cortical activation and specialization. Several fMRI studies have provided evidence of underconnectivity in distributed cortical networks subserving core symptoms of ASDs. In addition, abnormalities in the DMN have been identified during the resting state. This is of particular importance given the DMNs hypothesized involvement in higher-order social cognitive processes such as theory of mind.

In summary, sMRI and fMRI research to date has meaningfully informed our understanding of brain structure, composition, and function in ASDs. As such, it has made invaluable contributions to our understanding of the neurobiology of these profound disorders. However, existing investigations have been fraught with limitations such as small sample sizes, cross-sectional designs, heterogeneous subject characteristics, and varying methodologies. Neuroimaging studies that address these limitations, as well as incorporate multiple structural and functional techniques, will have greater potential to positively impact the field.

\section{Experimental procedures}

A PubMed search was conducted from 1966 to 2010 using the search terms autism, autism spectrum disorders, default-mode network, diffusion tensor imaging, functional magnetic resonance imaging, neuroimaging, pervasive developmental disorders, and structural magnetic resonance imaging, with additional publications obtained from articles identified in the search. 


\section{Acknowledgments}

This work was supported in part by a research grant (RO1 MH072964) from the National Institute of Mental Health (NIMH) (Dr. McDougle), a Career Development Award (K23 MH082119) from the NIMH (Dr. Stigler), and a Daniel X. and Mary Freedman Foundation in Academic Psychiatry Fellowship Award (Dr. Stigler).

\section{REFERENCES}

Abell F, Krams M, Ashburner J, Passingham R, Friston K, Frackowiak R, Happe F, Frith C, Frith U. The neuroanatomy of autism: a voxel-based whole brain analysis of structural scans. NeuroReport. 1999; 10:1647-1651. [PubMed: 10501551]

Adolphs R. Fear, faces, and the human amygdala. Curr. Opin. Neurobiol. 2008; 18:166-172. [PubMed: 18655833]

Akshoomoff N, Lord C, Lincoln AJ, Courchesne RY, Carper RA, Townsend J, Courchesne E. Outcome classification of preschool children with autism spectrum disorders using MRI brain measures. J. Am. Acad. Child Adolesc. Psychiatry. 2004; 43:349-357. [PubMed: 15076269]

Alexander AL, Lee JE, Lazar M, Boudos R, DuBray MB, Oakes TR, Miller JN, Lu J, Jeong EK, McMahon WM, Bigler ED, Lainhart JE. Diffusion tensor imaging of the corpus callosum in autism. Neuroimage. 2007; 34:61-73. [PubMed: 17023185]

Allison T, Puce A, McCarthy G. Social perception from visual cues: role of the STS region. Trends Cogn. Sci. 2000; 4:267-278. [PubMed: 10859571]

Amaral DG, Schumann CM, Nordahl CW. Neuroanatomy of autism. Trends Neurosci. 2008; 31:137145. [PubMed: 18258309]

American Psychiatric Association. Diagnostic and Statistical Manual of Mental Disorders. American Psychiatric Association; Washington, DC: 2000.

Assaf M, Jagannathan K, Calhoun VD, Miller L, Stevens MC, Sahl R, O'Boyle JG, Schultz RT, Pearlson GD. Abnormal functional connectivity of default mode sub-networks in autism spectrum disorder patients. Neuroimage. 2010

Aylward EH, Minshew NJ, Goldstein G, Honeycutt NA, Augustine AM, Yates KO, Barta PE, Pearlson GD. MRI volumes of amygdala and hippocampus in non-mentally retarded autistic adolescents and adults. Neurology. 1999; 53:2145-2150. [PubMed: 10599796]

Aylward EH, Minshew NJ, Field K, Sparks BF, Singh N. Effects of age on brain volume and head circumference in autism. Neurology. 2002; 59:175-183. [PubMed: 12136053]

Bailey A, Luthert P, Bolton P, Le Couteur A, Rutter M, Harding B. Autism and megalencephaly. Lancet. 1993; 341:1225-1226. [PubMed: 8098126]

Bailey A, Le Couteur A, Gottesman I, Bolton P, Simonoff E, Yuzda E, Rutter M. Autism as a strongly genetic disorder: evidence from a British twin study. Psychol. Med. 1995; 25:63-77. [PubMed: 7792363]

Barnea-Goraly N, Kwon H, Menon V, Eliez S, Lotspeich L, Reiss AL. White matter structure in autism: preliminary evidence from diffusion tensor imaging. Biol. Psychiatry. 2004; 55:323-326. [PubMed: 14744477]

Baron-Cohen S, Scott FJ, Allison C, Williams J, Bolton P, Matthews FE, Brayne C. Prevalence of autism-spectrum conditions: UK school-based population study. Br. J. Psychiatry. 2009; 194:500509. [PubMed: 19478287]

Bartholomeusz HH, Courchesne E, Karns CM. Relationship between head circumference and brain volume in healthy normal toddlers, children, and adults. Neuropediatrics. 2002; 33:239-241. [PubMed: 12536365]

Bigler ED, Tate DF, Neeley ES, Wolfson LJ, Miller MJ, Rice SA, Cleavinger H, Anderson C, Coon H, Ozonoff S, Johnson M, Dinh E, Lu J, McMahon W, Lainhart JE. Temporal lobe, autism, and macrocephaly. AJNR Am. J. Neuroradiol. 2003; 24:2066-2076. [PubMed: 14625235]

Bloemen OJ, Deeley Q, Sundram F, Daly EM, Barker GJ, Jones DK, van Amelsvoort TA, Schmitz N, Robertson D, Murphy KC, Murphy DG. White matter integrity in Asperger syndrome: a preliminary diffusion tensor magnetic resonance imaging study in adults. Autism. Res. 2010 
Boddaert N, Chabane N, Gervais H, Good CD, Bourgeois M, Plumet MH, Barthelemy C, Mouren MC, Artiges E, Samson Y, Brunelle F, Frackowiak RS, Zilbovicius M. Superior temporal sulcus anatomical abnormalities in childhood autism: a voxel-based morphometry MRI study. Neuroimage. 2004; 23:364-369. [PubMed: 15325384]

Bonilha L, Cendes F, Rorden C, Eckert M, Dalgalarrondo P, Li LM, Steiner CE. Gray and white matter imbalance-typical structural abnormality underlying classic autism? Brain Dev. 2008; 30:396-401. [PubMed: 18362056]

Bookheimer S. Functional MRI of language: new approaches to understanding the cortical organization of semantic processing. Annu. Rev. Neurosci. 2002; 25:151-188. [PubMed: 12052907]

Brambilla P, Hardan A, di Nemi SU, Perez J, Soares JC, Barale F. Brain anatomy and development in autism: review of structural MRI studies. Brain Res. Bull. 2003; 61:557-569. [PubMed: 14519452]

Brito AR, Vasconcelos MM, Domingues RC, HyginodaCruz LC Jr. Rodrigues Lde S, Gasparetto EL, Calcada CA. Diffusion tensor imaging findings in school-aged autistic children. J. Neuroimaging. 2009; 19:337-343. [PubMed: 19490374]

Broyd SJ, Demanuele C, Debener S, Helps SK, James CJ, Sonuga-Barke EJ. Default-mode brain dysfunction in mental disorders: a systematic review. Neurosci. Biobehav. Rev. 2009; 33:279-296. [PubMed: 18824195]

Brun CC, Nicolson R, Lepore N, Chou YY, Vidal CN, DeVito TJ, Drost DJ, Williamson PC, Rajakumar N, Toga AW, Thompson PM. Mapping brain abnormalities in boys with autism. Hum. Brain Mapp. 2009; 30:3887-3900. [PubMed: 19554561]

Buxbaum LJ, Kyle KM, Menon R. On beyond mirror neurons: internal representations subserving imitation and recognition of skilled object-related actions in humans. Brain Res. Cogn. Brain Res. 2005; 25:226-239. [PubMed: 15996857]

Campbell M, Rosenbloom S, Perry R, George AE, Kricheff II, Anderson L, Small AM, Jennings SJ. Computerized axial tomography in young autistic children. Am. J. Psychiatry. 1982; 139:510-512. [PubMed: 7065302]

Carper RA, Courchesne E. Localized enlargement of the frontal cortex in early autism. Biol. Psychiatry. 2005; 57:126-133. [PubMed: 15652870]

Carper RA, Moses P, Tigue ZD, Courchesne E. Cerebral lobes in autism: early hyperplasia and abnormal age effects. Neuroimage. 2002; 16:1038-1051. [PubMed: 12202091]

Castelli F, Frith C, Happe F, Frith U. Autism, Asperger syndrome and brain mechanisms for the attribution of mental states to animated shapes. Brain. 2002; 125:1839-1849. [PubMed: 12135974]

Catani M, Jones DK, Daly E, Embiricos N, Deeley Q, Pugliese L, Curran S, Robertson D, Murphy DG. Altered cerebellar feedback projections in Asperger syndrome. Neuroimage. 2008; 41:11841191. [PubMed: 18495494]

Cattaneo L, Rizzolatti G. The mirror neuron system. Arch. Neurol. 2009; 66:557-560. [PubMed: 19433654]

Cherkassky VL, Kana RK, Keller TA, Just MA. Functional connectivity in a baseline resting-state network in autism. NeuroReport. 2006; 17:1687-1690. [PubMed: 17047454]

Cheung C, Chua SE, Cheung V, Khong PL, Tai KS, Wong TK, Ho TP, McAlonan GM. White matter fractional anisotrophy differences and correlates of diagnostic symptoms in autism. J. Child Psychol. Psychiatry. 2009; 50:1102-1112. [PubMed: 19490309]

Chung MK, Dalton KM, Alexander AL, Davidson RJ. Less white matter concentration in autism: 2D voxel-based morphometry. Neuroimage. 2004; 23:242-251. [PubMed: 15325371]

Corbett BA, Carmean V, Ravizza S, Wendelken C, Henry ML, Carter C, Rivera SM. A functional and structural study of emotion and face processing in children with autism. Psychiatry Res. 2009; 173:196-205. [PubMed: 19665877]

Courchesne E, Yeung-Courchesne R, Press GA, Hesselink JR, Jernigan TL. Hypoplasia of cerebellar vermal lobules VI and VII in autism. N. Engl. J. Med. 1988; 318:1349-1354. [PubMed: 3367935]

Courchesne E, Saitoh O, Yeung-Courchesne R, Press GA, Lincoln AJ, Haas RH, Schreibman L. Abnormality of cerebellar vermian lobules VI and VII in patients with infantile autism: 
identification of hypoplastic and hyperplastic subgroups with MR imaging. AJR Am. J. Roentgenol. 1994; 162:123-130. [PubMed: 8273650]

Courchesne E, Karns CM, Davis HR, Ziccardi R, Carper RA, Tigue ZD, Chisum HJ, Moses P, Pierce K, Lord C, Lincoln AJ, Pizzo S, Schreibman L, Haas RH, Akshoomoff NA, Courchesne RY. Unusual brain growth patterns in early life in patients with autistic disorder: an MRI study. Neurology. 2001; 57:245-254. [PubMed: 11468308]

Courchesne E, Carper R, Akshoomoff N. Evidence of brain overgrowth in the first year of life in autism. JAMA. 2003; 290:337-344. [PubMed: 12865374]

Courchesne E, Pierce K, Schumann CM, Redcay E, Buckwalter JA, Kennedy DP, Morgan J. Mapping early brain development in autism. Neuron. 2007; 56:399-413. [PubMed: 17964254]

Craig MC, Zaman SH, Daly EM, Cutter WJ, Robertson DM, Hallahan B, Toal F, Reed S, Ambikapathy A, Brammer M, Murphy CM, Murphy DG. Women with autistic-spectrum disorder: magnetic resonance imaging study of brain anatomy. Br. J. Psychiatry. 2007; 191:224-228. [PubMed: 17766762]

Critchley HD, Daly EM, Bullmore ET, Williams SC, Van Amelsvoort T, Robertson DM, Rowe A, Phillips M, McAlonan G, Howlin P, Murphy DG. The functional neuroanatomy of social behaviour: changes in cerebral blood flow when people with autistic disorder process facial expressions. Brain. 2000; 123(Pt 11):2203-2212. [PubMed: 11050021]

Dalton KM, Nacewicz BM, Johnstone T, Schaefer HS, Gernsbacher MA, Goldsmith HH, Alexander AL, Davidson RJ. Gaze fixation and the neural circuitry of face processing in autism. Nat. Neurosci. 2005; 8:519-526. [PubMed: 15750588]

Damasio H, Maurer RG, Damasio AR, Chui HC. Computerized tomographic scan findings in patients with autistic behavior. Arch. Neurol. 1980; 37:504-510. [PubMed: 6968201]

Dapretto M, Davies MS, Pfeifer JH, Scott AA, Sigman M, Bookheimer SY, Iacoboni M. Understanding emotions in others: mirror neuron dysfunction in children with autism spectrum disorders. Nat. Neurosci. 2006; 9:28-30. [PubMed: 16327784]

Dawson G, Webb SJ, McPartland J. Understanding the nature of face processing impairment in autism: insights from behavioral and electrophysiological studies. Dev. Neuropsychol. 2005; 27:403-424. [PubMed: 15843104]

Dawson G, Munson J, Webb SJ, Nalty T, Abbott R, Toth K. Rate of head growth decelerates and symptoms worsen in the second year of life in autism. Biol. Psychiatry. 2007; 61:458-464. [PubMed: 17137564]

DeFosse L, Hodge SM, Makris N, Kennedy DN, Caviness VS Jr. McGrath L, Steele S, Ziegler DA, Herbert MR, Frazier JA, Tager-Flusberg H, Harris GJ. Language-association cortex asymmetry in autism and specific language impairment. Ann. Neurol. 2004; 56:757-766. [PubMed: 15478219]

Dementieva YA, Vance DD, Donnelly SL, Elston LA, Wolpert CM, Ravan SA, DeLong GR, Abramson RK, Wright HH, Cuccaro ML. Accelerated head growth in early development of individuals with autism. Pediatr. Neurol. 2005; 32:102-108. [PubMed: 15664769]

Dichter GS, Belger A. Social stimuli interfere with cognitive control in autism. Neuroimage. 2007; 35:1219-1230. [PubMed: 17321151]

Dichter GS, Belger A. Atypical modulation of cognitive control by arousal in autism. Psychiatry Res. 2008; 164:185-197. [PubMed: 18954965]

Dinstein I, Thomas C, Humphreys K, Minshew N, Behrmann M, Heeger DJ. Normal movement selectivity in autism. Neuron. 2010; 66:461-469. [PubMed: 20471358]

Ebisch SJ, Gallese V, Willems RM, Mantini D, Groen WB, Romani GL, Buitelaar JK, Bekkering H. Altered intrinsic functional connectivity of anterior and posterior insula regions in highfunctioning participants with autism spectrum disorder. Hum Brain Mapp. 2010

Egaas B, Courchesne E, Saitoh O. Reduced size of corpus callosum in autism. Arch. Neurol. 1995; 52:794-801. [PubMed: 7639631]

Elia M, Ferri R, Musumeci SA, Panerai S, Bottitta M, Scuderi C. Clinical correlates of brain morphometric features of subjects with low-functioning autistic disorder. J. Child Neurol. 2000; 15:504-508. [PubMed: 10961787]

Fernell E, Gillberg C. Autism spectrum disorder diagnoses in Stockholm preschoolers. Res. Dev. Disabil. 2010; 31:680-685. [PubMed: 20149593] 
Fombonne E. Is a large head circumference a sign of autism? J. Autism Dev. Disord. 2000; 30:365. [PubMed: 11039865]

Frazier TW, Hardan AY. A meta-analysis of the corpus callosum in autism. Biol. Psychiatry. 2009; 66:935-941. [PubMed: 19748080]

Freitag CM, Luders E, Hulst HE, Narr KL, Thompson PM, Toga AW, Krick C, Konrad C. Total brain volume and corpus callosum size in medication-naive adolescents and young adults with autism spectrum disorder. Biol. Psychiatry. 2009; 66:316-319. [PubMed: 19409535]

Frith U, Frith CD. Development and neurophysiology of mentalizing. Philos. Trans. R. Soc. Lond. B Biol. Sci. 2003; 358:459-473. [PubMed: 12689373]

Gaffney GR, Tsai LY. Magnetic resonance imaging of high level autism. J. Autism Dev. Disord. 1987; 17:433-438. [PubMed: 3654494]

Gaffney GR, Kuperman S, Tsai LY, Minchin S. Morphological evidence for brainstem involvement in infantile autism. Biol. Psychiatry. 1988; 24:578-586. [PubMed: 3167146]

Gaffrey MS, Kleinhans NM, Haist F, Akshoomoff N, Campbell A, Courchesne E, Muller RA. Atypical [corrected] participation of visual cortex during word processing in autism: an fMRI study of semantic decision. Neuropsychologia. 2007; 45:1672-1684. [PubMed: 17336346]

Garber HJ, Ritvo ER. Magnetic resonance imaging of the posterior fossa in autistic adults. Am. J. Psychiatry. 1992; 149:245-247. [PubMed: 1734747]

Gilbert SJ, Meuwese JD, Towgood KJ, Frith CD, Burgess PW. Abnormal functional specialization within medial prefrontal cortex in high-functioning autism: a multi-voxel similarity analysis. Brain. 2009; 132:869-878. [PubMed: 19174370]

Girgis RR, Minshew NJ, Melhem NM, Nutche JJ, Keshavan MS, Hardan AY. Volumetric alterations of the orbitofrontal cortex in autism. Prog. Neuropsychopharmacol. Biol. Psychiatry. 2007; 31:4145. [PubMed: 16863674]

Greimel E, Schulte-Ruther M, Kircher T, Kamp-Becker I, Remschmidt H, Fink GR, HerpertzDahlmann B, Konrad K. Neural mechanisms of empathy in adolescents with autism spectrum disorder and their fathers. Neuroimage. 2010; 49:1055-1065. [PubMed: 19647799]

Groen WB, Zwiers MP, van der Gaag RJ, Buitelaar JK. The phenotype and neural correlates of language in autism: an integrative review. Neurosci. Biobehav. Rev. 2008; 32:1416-1425. [PubMed: 18562003]

Hadjikhani N, Joseph RM, Snyder J, Chabris CF, Clark J, Steele S, McGrath L, Vangel M, Aharon I, Feczko E, Harris GJ, Tager-Flusberg H. Activation of the fusiform gyrus when individuals with autism spectrum disorder view faces. Neuroimage. 2004; 22:1141-1150. [PubMed: 15219586]

Hadjikhani N, Joseph RM, Snyder J, Tager-Flusberg H. Anatomical differences in the mirror neuron system and social cognition network in autism. Cereb. Cortex. 2006; 16:1276-1282. [PubMed: 16306324]

Hardan AY, Minshew NJ, Keshavan MS. Corpus callosum size in autism. Neurology. 2000; 55:10331036. [PubMed: 11061265]

Hardan AY, Minshew NJ, Harenski K, Keshavan MS. Posterior fossa magnetic resonance imaging in autism. J. Am. Acad. Child Adolesc. Psychiatry. 2001a; 40:666-672. [PubMed: 11392344]

Hardan AY, Minshew NJ, Mallikarjuhn M, Keshavan MS. Brain volume in autism. J. Child Neurol. 2001b; 16:421-424. [PubMed: 11417608]

Hardan AY, Girgis RR, Adams J, Gilbert AR, Keshavan MS, Minshew NJ. Abnormal brain size effect on the thalamus in autism. Psychiatry Res. 2006a; 147:145-151. [PubMed: 16945509]

Hardan AY, Girgis RR, Lacerda AL, Yorbik O, Kilpatrick M, Keshavan MS, Minshew NJ. Magnetic resonance imaging study of the orbitofrontal cortex in autism. J. Child Neurol. 2006b; 21:866871. [PubMed: 17005103]

Hardan AY, Muddasani S, Vemulapalli M, Keshavan MS, Minshew NJ. An MRI study of increased cortical thickness in autism. Am. J. Psychiatry. 2006c; 163:1290-1292. [PubMed: 16816240]

Hardan AY, Minshew NJ, Melhem NM, Srihari S, Jo B, Bansal R, Keshavan MS, Stanley JA. An MRI and proton spectroscopy study of the thalamus in children with autism. Psychiatry Res. 2008; 163:97-105. [PubMed: 18508243] 
Hardan AY, Libove RA, Keshavan MS, Melhem NM, Minshew NJ. A preliminary longitudinal magnetic resonance imaging study of brain volume and cortical thickness in autism. Biol. Psychiatry. 2009a; 66:320-326. [PubMed: 19520362]

Hardan AY, Pabalan M, Gupta N, Bansal R, Melhem NM, Fedorov S, Keshavan MS, Minshew NJ. Corpus callosum volume in children with autism. Psychiatry Res. 2009b; 174:57-61. [PubMed: 19781917]

Harris GJ, Chabris CF, Clark J, Urban T, Aharon I, Steele S, McGrath L, Condouris K, Tager-Flusberg $\mathrm{H}$. Brain activation during semantic processing in autism spectrum disorders via functional magnetic resonance imaging. Brain Cogn. 2006; 61:54-68. [PubMed: 16473449]

Hashimoto T, Murakawa K, Miyazaki M, Tayama M, Kuroda Y. Magnetic resonance imaging of the brain structures in the posterior fossa in retarded autistic children. Acta Paediatr. 1992; 81:1030 1034. [PubMed: 1290848]

Hashimoto T, Tayama M, Murakawa K, Yoshimoto T, Miyazaki M, Harada M, Kuroda Y. Development of the brainstem and cerebellum in autistic patients. J. Autism Dev. Disord. 1995; 25:1-18. [PubMed: 7608030]

Haxby JV, Hoffman EA, Gobbini MI. Human neural systems for face recognition and social communication. Biol. Psychiatry. 2002; 51:59-67. [PubMed: 11801231]

Hazlett HC, Poe M, Gerig G, Smith RG, Provenzale J, Ross A, Gilmore J, Piven J. Magnetic resonance imaging and head circumference study of brain size in autism: birth through age 2 years. Arch. Gen. Psychiatry. 2005; 62:1366-1376. [PubMed: 16330725]

Hazlett HC, Poe MD, Gerig G, Smith RG, Piven J. Cortical gray and white brain tissue volume in adolescents and adults with autism. Biol. Psychiatry. 2006; 59:1-6. [PubMed: 16139816]

Haznedar MM, Buchsbaum MS, Metzger M, Solimando A, Spiegel-Cohen J, Hollander E. Anterior cingulate gyrus volume and glucose metabolism in autistic disorder. Am. J. Psychiatry. 1997; 154:1047-1050. [PubMed: 9247387]

Haznedar MM, Buchsbaum MS, Wei TC, Hof PR, Cartwright C, Bienstock CA, Hollander E. Limbic circuitry in patients with autism spectrum disorders studied with positron emission tomography and magnetic resonance imaging. Am. J. Psychiatry. 2000; 157:1994-2001. [PubMed: 11097966]

Haznedar MM, Buchsbaum MS, Hazlett EA, LiCalzi EM, Cartwright C, Hollander E. Volumetric analysis and three-dimensional glucose metabolic mapping of the striatum and thalamus in patients with autism spectrum disorders. Am. J. Psychiatry. 2006; 163:1252-1263. [PubMed: 16816232]

Herbert MR, Harris GJ, Adrien KT, Ziegler DA, Makris N, Kennedy DN, Lange NT, Chabris CF, Bakardjiev A, Hodgson J, Takeoka M, Tager-Flusberg H, Caviness VS Jr. Abnormal asymmetry in language association cortex in autism. Ann. Neurol. 2002; 52:588-596. [PubMed: 12402256]

Herbert MR, Ziegler DA, Deutsch CK, O'Brien LM, Lange N, Bakardjiev A, Hodgson J, Adrien KT, Steele S, Makris N, Kennedy D, Harris GJ, Caviness VS Jr. Dissociations of cerebral cortex, subcortical and cerebral white matter volumes in autistic boys. Brain. 2003; 126:1182-1192. [PubMed: 12690057]

Herbert MR, Ziegler DA, Makris N, Filipek PA, Kemper TL, Normandin JJ, Sanders HA, Kennedy DN, Caviness VS Jr. Localization of white matter volume increase in autism and developmental language disorder. Ann. Neurol. 2004; 55:530-540. [PubMed: 15048892]

Hodge SM, Makris N, Kennedy DN, Caviness VS Jr. Howard J, McGrath L, Steele S, Frazier JA, Tager-Flusberg H, Harris GJ. Cerebellum, language, and cognition in autism and specific language impairment. J. Autism Dev. Disord. 2010; 40:300-316. [PubMed: 19924522]

Hoffman EA, Haxby JV. Distinct representations of eye gaze and identity in the distributed human neural system for face perception. Nat. Neurosci. 2000; 3:80-84. [PubMed: 10607399]

Hollander E, Anagnostou E, Chaplin W, Esposito K, Haznedar MM, Licalzi E, Wasserman S, Soorya L, Buchsbaum M. Striatal volume on magnetic resonance imaging and repetitive behaviors in autism. Biol. Psychiatry. 2005; 58:226-232. [PubMed: 15939406]

Holttum JR, Minshew NJ, Sanders RS, Phillips NE. Magnetic resonance imaging of the posterior fossa in autism. Biol. Psychiatry. 1992; 32:1091-1101. [PubMed: 1477189]

Howard MA, Cowell PE, Boucher J, Broks P, Mayes A, Farrant A, Roberts N. Convergent neuroanatomical and behavioural evidence of an amygdala hypothesis of autism. NeuroReport. 2000; 11:2931-2935. [PubMed: 11006968] 
Hubl D, Bolte S, Feineis-Matthews S, Lanfermann H, Federspiel A, Strik W, Poustka F, Dierks T. Functional imbalance of visual pathways indicates alternative face processing strategies in autism. Neurology. 2003; 61:1232-1237. [PubMed: 14610126]

Huettel, SA.; Song, AW.; McCarthy, G., editors. Functional Magnetic Resonance Imaging, Second Edition. Sinauer Associates, Inc.; Sunderland, MA: 2009.

Humphreys K, Hasson U, Avidan G, Minshew N, Behrmann M. Cortical patterns of category-selective activation for faces, places and objects in adults with autism. Autism Res. 2008; 1:52-63. [PubMed: 19360650]

Hyde KL, Samson F, Evans AC, Mottron L. Neuroanatomical differences in brain areas implicated in perceptual and other core features of autism revealed by cortical thickness analysis and voxelbased morphometry. Hum. Brain Mapp. 2010; 31:556-566. [PubMed: 19790171]

Iacoboni M, Woods RP, Brass M, Bekkering H, Mazziotta JC, Rizzolatti G. Cortical mechanisms of human imitation. Science. 1999; 286:2526-2528. [PubMed: 10617472]

Johnson-Frey SH, Maloof FR, Newman-Norlund R, Farrer C, Inati S, Grafton ST. Actions or handobject interactions? Human inferior frontal cortex and action observation. Neuron. 2003; 39:1053-1058. [PubMed: 12971903]

Jou RJ, Minshew NJ, Melhem NM, Keshavan MS, Hardan AY. Brainstem volumetric alterations in children with autism. Psychol. Med. 2009; 39:1347-1354. [PubMed: 18812009]

Jou RJ, Minshew NJ, Keshavan MS, Hardan AY. Cortical gyrification in autistic and Asperger disorders: a preliminary magnetic resonance imaging study. J. Child. Neurol. 2010

Just MA, Cherkassky VL, Keller TA, Minshew NJ. Cortical activation and synchronization during sentence comprehension in high-functioning autism: evidence of underconnectivity. Brain. 2004; 127:1811-1821. [PubMed: 15215213]

Just MA, Cherkassky VL, Keller TA, Kana RK, Minshew NJ. Functional and anatomical cortical underconnectivity in autism: evidence from an FMRI study of an executive function task and corpus callosum morphometry. Cereb. Cortex. 2007; 17:951-961. [PubMed: 16772313]

Kana RK, Keller TA, Cherkassky VL, Minshew NJ, Just MA. Sentence comprehension in autism: thinking in pictures with decreased functional connectivity. Brain. 2006; 129:2484-2493. [PubMed: 16835247]

Kana RK, Keller TA, Minshew NJ, Just MA. Inhibitory control in high-functioning autism: decreased activation and underconnectivity in inhibition networks. Biol. Psychiatry. 2007; 62:198-206. [PubMed: 17137558]

Kanner L. Autistic disturbances of affective contact. Nerv. Child. 1943; 2:217-250.

Kates WR, Ikuta I, Burnette CP. Gyrification patterns in monozygotic twin pairs varying in discordance for autism. Autism Res. 2009; 2:267-278. [PubMed: 19890876]

Katz LC, Shatz CJ. Synaptic activity and the construction of cortical circuits. Science. 1996; 274:1133-1138. [PubMed: 8895456]

Kaufmann WE, Cooper KL, Mostofsky SH, Capone GT, Kates WR, Newschaffer CJ, Bukelis I, Stump MH, Jann AE, Lanham DC. Specificity of cerebellar vermian abnormalities in autism: a quantitative magnetic resonance imaging study. J. Child Neurol. 2003; 18:463-470. [PubMed: 12940651]

Keary CJ, Minshew NJ, Bansal R, Goradia D, Fedorov S, Keshavan MS, Hardan AY. Corpus callosum volume and neurocognition in autism. J. Autism Dev. Disord. 2009; 39:834-841. [PubMed: 19165587]

Keller TA, Kana RK, Just MA. A developmental study of the structural integrity of white matter in autism. NeuroReport. 2007; 18:23-27. [PubMed: 17259855]

Kemper TL, Bauman M. Neuropathology of infantile autism. J. Neuropathol. Exp. Neurol. 1998; 57:645-652. [PubMed: 9690668]

Kennedy DP, Courchesne E. Functional abnormalities of the default network during self- and otherreflection in autism. Soc. Cogn. Affect. Neurosci. 2008a; 3:177-190. [PubMed: 19015108]

Kennedy DP, Courchesne E. The intrinsic functional organization of the brain is altered in autism. Neuroimage. 2008b; 39:1877-1885. [PubMed: 18083565]

Kennedy DP, Redcay E, Courchesne E. Failing to deactivate: resting functional abnormalities in autism. Proc. Natl Acad. Sci. USA. 2006; 103:8275-8280. [PubMed: 16702548] 
Kleiman MD, Neff S, Rosman NP. The brain in infantile autism: are posterior fossa structures abnormal? Neurology. 1992; 42:753-760. [PubMed: 1565227]

Kleinhans NM, Muller RA, Cohen DN, Courchesne E. Atypical functional lateralization of language in autism spectrum disorders. Brain Res. 2008a; 1221:115-125. [PubMed: 18555209]

Kleinhans NM, Richards T, Sterling L, Stegbauer KC, Mahurin R, Johnson LC, Greenson J, Dawson G, Aylward E. Abnormal functional connectivity in autism spectrum disorders during face processing. Brain. 2008b; 131:1000-1012. [PubMed: 18234695]

Kleinhans NM, Johnson LC, Richards T, Mahurin R, Greenson J, Dawson G, Aylward E. Reduced neural habituation in the amygdala and social impairments in autism spectrum disorders. American Journal of Psychiatry. 2009

Kleinhans NM, Richards T, Johnson LC, Weaver KE, Greenson J, Dawson G, Aylward E. fMRI evidence of neural abnormalities in the subcortical face processing system in ASD. Neuroimage. 2010

Klin A, Klin A. Three things to remember if you are a functional magnetic resonance imaging researcher of face processing in autism spectrum disorders. Biol. Psychiatry. 2008; 64:549-551. [PubMed: 18778978]

Klin A, Jones W, Schultz R, Volkmar F, Cohen D. Visual fixation patterns during viewing of naturalistic social situations as predictors of social competence in individuals with autism. Arch. Gen. Psychiatry. 2002; 59:809-816. [PubMed: 12215080]

Knaus TA, Silver AM, Lindgren KA, Hadjikhani N, Tager-Flusberg H. fMRI activation during a language task in adolescents with ASD. J. Int. Neuropsychol. Soc. 2008; 14:967-979. [PubMed: 18954477]

Knaus TA, Silver AM, Dominick KC, Schuring MD, Shaffer N, Lindgren KA, Joseph RM, TagerFlusberg $\mathrm{H}$. Age-related changes in the anatomy of language regions in autism spectrum disorder. Brain Imaging Behav. 2009; 3:51-63. [PubMed: 20161060]

Korkmaz B, Benbir G, Demirbilek V. Migration abnormality in the left cingulate gyrus presenting with autistic disorder. J. Child Neurol. 2006; 21:600-604. [PubMed: 16970852]

Kosaka H, Omori M, Munesue T, Ishitobi M, Matsumura Y, Takahashi T, Narita K, Murata T, Saito DN, Uchiyama H, Morita T, Kikuchi M, Mizukami K, Okazawa H, Sadato N, Wada Y. Smaller insula and inferior frontal volumes in young adults with pervasive developmental disorders. Neuroimage. 2010; 50:1357-1363. [PubMed: 20123027]

Koshino H, Carpenter PA, Minshew NJ, Cherkassky VL, Keller TA, Just MA. Functional connectivity in an fMRI working memory task in high-functioning autism. Neuroimage. 2005; 24:810-821. [PubMed: 15652316]

Kwon H, Ow AW, Pedatella KE, Lotspeich LJ, Reiss AL. Voxel-based morphometry elucidates structural neuroanatomy of high-functioning autism and Asperger syndrome. Dev. Med. Child Neurol. 2004; 46:760-764. [PubMed: 15540637]

Lainhart JE, Piven J, Wzorek M, Landa R, Santangelo SL, Coon H, Folstein SE. Macrocephaly in children and adults with autism. J. Am. Acad. Child Adolesc. Psychiatry. 1997; 36:282-290. [PubMed: 9031582]

Lainhart JE, Bigler ED, Bocian M, Coon H, Dinh E, Dawson G, Deutsch CK, Dunn M, Estes A, Tager-Flusberg H, Folstein S, Hepburn S, Hyman S, McMahon W, Minshew N, Munson J, Osann K, Ozonoff S, Rodier P, Rogers S, Sigman M, Spence MA, Stodgell CJ, Volkmar F. Head circumference and height in autism: a study by the Collaborative Program of Excellence in Autism. Am. J. Med. Genet. A. 2006; 140:2257-2274. [PubMed: 17022081]

Langen M, Durston S, Staal WG, Palmen SJ, van Engeland H. Caudate nucleus is enlarged in highfunctioning medication-naive subjects with autism. Biol. Psychiatry. 2007; 62:262-266. [PubMed: 17224135]

Langen M, Schnack HG, Nederveen H, Bos D, Lahuis BE, de Jonge MV, van Engeland H, Durston S. Changes in the developmental trajectories of striatum in autism. Biol. Psychiatry. 2009; 66:327333. [PubMed: 19423078]

Lee JE, Bigler ED, Alexander AL, Lazar M, DuBray MB, Chung MK, Johnson M, Morgan J, Miller JN, McMahon WM, Lu J, Jeong EK, Lainhart JE. Diffusion tensor imaging of white matter in the 
superior temporal gyrus and temporal stem in autism. Neurosci. Lett. 2007; 424:127-132. [PubMed: 17714869]

Levitt JG, Blanton RE, Smalley S, Thompson PM, Guthrie D, McCracken JT, Sadoun T, Heinichen L, Toga AW. Cortical sulcal maps in autism. Cereb. Cortex. 2003; 13:728-735. [PubMed: 12816888]

Lombardo MV, Chakrabarti B, Bullmore ET, Sadek SA, Pasco G, Wheelwright SJ, Suckling J, BaronCohen S. Atypical neural self-representation in autism. Brain. 2010; 133:611-624. [PubMed: 20008375]

Lopez BR, Lincoln AJ, Ozonoff S, Lai Z. Examining the relationship between executive functions and restricted, repetitive symptoms of autistic disorder. J. Autism Dev. Disord. 2005; 35:445-460. [PubMed: 16134030]

Luna B, Minshew NJ, Garver KE, Lazar NA, Thulborn KR, Eddy WF, Sweeney JA. Neocortical system abnormalities in autism: an fMRI study of spatial working memory. Neurology. 2002; 59:834-840. [PubMed: 12297562]

Manes F, Piven J, Vrancic D, Nanclares V, Plebst C, Starkstein SE. An MRI study of the corpus callosum and cerebellum in mentally retarded autistic individuals. J. Neuropsychiatry Clin. Neurosci. 1999; 11:470-474. [PubMed: 10570760]

Martineau J, Andersson F, Barthelemy C, Cottier JP, Destrieux C. Atypical activation of the mirror neuron system during perception of hand motion in autism. Brain Res. 2010; 1320:168-175. [PubMed: 20096269]

Mason RA, Williams DL, Kana RK, Minshew N, Just MA. Theory of mind disruption and recruitment of the right hemisphere during narrative comprehension in autism. Neuropsychologia. 2008; 46:269-280. [PubMed: 17869314]

McAlonan GM, Cheung V, Cheung C, Suckling J, Lam GY, Tai KS, Yip L, Murphy DG, Chua SE. Mapping the brain in autism. A voxel-based MRI study of volumetric differences and intercorrelations in autism. Brain. 2005; 128:268-276. [PubMed: 15548557]

McAlonan GM, Suckling J, Wong N, Cheung V, Lienenkaemper N, Cheung C, Chua SE. Distinct patterns of grey matter abnormality in high-functioning autism and Asperger's syndrome. J. Child Psychol. Psychiatry. 2008; 49:1287-1295. [PubMed: 18673405]

Menon V, Uddin LQ. Saliency, switching, attention and control: a network model of insula function. Brain Struct. Funct. 2010; 214:655-667. [PubMed: 20512370]

Mitchell SR, Reiss AL, Tatusko DH, Ikuta I, Kazmerski DB, Botti JA, Burnette CP, Kates WR. Neuroanatomic alterations and social and communication deficits in monozygotic twins discordant for autism disorder. Am. J. Psychiatry. 2009; 166:917-925. [PubMed: 19605538]

Monk CS, Peltier SJ, Wiggins JL, Weng SJ, Carrasco M, Risi S, Lord C. Abnormalities of intrinsic functional connectivity in autism spectrum disorders. Neuroimage. 2009; 47:764-772. [PubMed: 19409498]

Monk CS, Weng SJ, Wiggins JL, Kurapati N, Louro HM, Carrasco M, Maslowsky J, Risi S, Lord C. Neural circuitry of emotional face processing in autism spectrum disorders. J. Psychiatry Neurosci. 2010; 35:105-114. [PubMed: 20184808]

Muller RA. From loci to networks and back again: anomalies in the study of autism. Ann. NY Acad. Sci. 2008; 1145:300-315. [PubMed: 19076405]

Munson J, Dawson G, Abbott R, Faja S, Webb SJ, Friedman SD, Shaw D, Artru A, Dager SR. Amygdalar volume and behavioral development in autism. Arch. Gen. Psychiatry. 2006; 63:686693. [PubMed: 16754842]

Nacewicz BM, Dalton KM, Johnstone T, Long MT, McAuliff EM, Oakes TR, Alexander AL, Davidson RJ. Amygdala volume and nonverbal social impairment in adolescent and adult males with autism. Arch. Gen. Psychiatry. 2006; 63:1417-1428. [PubMed: 17146016]

Nakada T, Fujii Y, Yoneoka Y, Kwee IL. Planum temporale: where spoken and written language meet. Eur. Neurol. 2001; 46:121-125. [PubMed: 11598329]

Nicolson R, DeVito TJ, Vidal CN, Sui Y, Hayashi KM, Drost DJ, Williamson PC, Rajakumar N, Toga AW, Thompson PM. Detection and mapping of hippocampal abnormalities in autism. Psychiatry Res. 2006; 148:11-21. [PubMed: 17056234] 
Nordahl CW, Dierker D, Mostafavi I, Schumann CM, Rivera SM, Amaral DG, Van Essen DC. Cortical folding abnormalities in autism revealed by surface-based morphometry. J. Neurosci. 2007; 27:11725-11735. [PubMed: 17959814]

Ornitz EM. The functional neuroanatomy of infantile autism. Int. J. Neurosci. 1983; 19:85-124. [PubMed: 6874265]

Palmen SJ, Hulshoff Pol HE, Kemner C, Schnack HG, Durston S, Lahuis BE, Kahn RS, Van Engeland $\mathrm{H}$. Increased gray-matter volume in medication-naive high-functioning children with autism spectrum disorder. Psychol. Med. 2005; 35:561-570. [PubMed: 15856726]

Pardini M, Garaci FG, Bonzano L, Roccatagliata L, Palmieri MG, Pompili E, Coniglione F, Krueger F, Ludovici A, Floris R, Benassi F, Emberti Gialloreti L. White matter reduced streamline coherence in young men with autism and mental retardation. Eur. J. Neurol. 2009; 16:11851190. [PubMed: 19538216]

Pelphrey KA, Sasson NJ, Reznick JS, Paul G, Goldman BD, Piven J. Visual scanning of faces in autism. J. Autism Dev. Disord. 2002; 32:249-261. [PubMed: 12199131]

Pelphrey KA, Morris JP, McCarthy G. Neural basis of eye gaze processing deficits in autism. Brain. 2005; 128:1038-1048. [PubMed: 15758039]

Pelphrey KA, Morris JP, McCarthy G, Labar KS. Perception of dynamic changes in facial affect and identity in autism. Soc. Cogn. Affect. Neurosci. 2007; 2:140-149. [PubMed: 18174910]

Pierce K, Redcay E. Fusiform function in children with an autism spectrum disorder is a matter of “who". Biol. Psychiatry. 2008; 64:552-560. [PubMed: 18621359]

Pierce K, Muller RA, Ambrose J, Allen G, Courchesne E. Face processing occurs outside the fusiform 'face area' in autism: evidence from functional MRI. Brain. 2001; 124:2059-2073. [PubMed: 11571222]

Pierce K, Haist F, Sedaghat F, Courchesne E. The brain response to personally familiar faces in autism: findings of fusiform activity and beyond. Brain. 2004; 127:2703-2716. [PubMed: 15319275]

Pierpaoli C, Jezzard P, Basser PJ, Barnett A, Di Chiro G. Diffusion tensor MR imaging of the human brain. Radiology. 1996; 201:637-648. [PubMed: 8939209]

Piggot J, Kwon H, Mobbs D, Blasey C, Lotspeich L, Menon V, Bookheimer S, Reiss AL. Emotional attribution in high-functioning individuals with autistic spectrum disorder: a functional imaging study. J. Am. Acad. Child Adolesc. Psychiatry. 2004; 43:473-480. [PubMed: 15187808]

Piven J, Nehme E, Simon J, Barta P, Pearlson G, Folstein SE. Magnetic resonance imaging in autism: measurement of the cerebellum, pons, and fourth ventricle. Biol. Psychiatry. 1992; 31:491-504. [PubMed: 1581425]

Piven J, Bailey J, Ranson BJ, Arndt S. An MRI study of the corpus callosum in autism. Am. J. Psychiatry. 1997; 154:1051-1056. [PubMed: 9247388]

Piven J, Bailey J, Ranson BJ, Arndt S. No difference in hippocampus volume detected on magnetic resonance imaging in autistic individuals. J. Autism Dev. Disord. 1998; 28:105-110. [PubMed: 9586772]

Premack D, Woodruff G. Chimpanzee problem-solving: a test for comprehension. Science. 1978; 202:532-535. [PubMed: 705342]

Puce A, Allison T, Bentin S, Gore JC, McCarthy G. Temporal cortex activation in humans viewing eye and mouth movements. J. Neurosci. 1998; 18:2188-2199. [PubMed: 9482803]

Pugliese L, Catani M, Ameis S, Dell'Acqua F, Thiebaut de Schotten M, Murphy C, Robertson D, Deeley Q, Daly E, Murphy DG. The anatomy of extended limbic pathways in Asperger syndrome: a preliminary diffusion tensor imaging tractography study. Neuroimage. 2009; 47:427-434. [PubMed: 19446642]

Redcay E, Courchesne E. When is the brain enlarged in autism? A meta-analysis of all brain size reports. Biol. Psychiatry. 2005; 58:1-9. [PubMed: 15935993]

Redcay E, Courchesne E. Deviant functional magnetic resonance imaging patterns of brain activity to speech in 2-3-year-old children with autism spectrum disorder. Biol. Psychiatry. 2008; 64:589598. [PubMed: 18672231]

Ritvo ER, Freeman BJ, Mason-Brothers A, Mo A, Ritvo AM. Concordance for the syndrome of autism in 40 pairs of afflicted twins. Am. J. Psychiatry. 1985; 142:74-77. [PubMed: 4038442] 
Rizzolatti G, Craighero L. The mirror-neuron system. Annu. Rev. Neurosci. 2004; 27:169-192. [PubMed: 15217330]

Rojas DC, Bawn SD, Benkers TL, Reite ML, Rogers SJ. Smaller left hemisphere planum temporale in adults with autistic disorder. Neurosci. Lett. 2002; 328:237-240. [PubMed: 12147315]

Rojas DC, Camou SL, Reite ML, Rogers SJ. Planum temporale volume in children and adolescents with autism. J. Autism Dev. Disord. 2005; 35:479-486. [PubMed: 16134033]

Rojas DC, Peterson E, Winterrowd E, Reite ML, Rogers SJ, Tregellas JR. Regional gray matter volumetric changes in autism associated with social and repetitive behavior symptoms. BMC Psychiatry. 2006; 6:56. [PubMed: 17166273]

Rosenbloom S, Campbell M, George AE, Kricheff II, Taleporos E, Anderson L, Reuben RN, Korein J. High resolution CT scanning in infantile autism: a quantitative approach. J. Am. Acad. Child Psychiatry. 1984; 23:72-77. [PubMed: 6607273]

Russo N, Flanagan T, Iarocci G, Berringer D, Zelazo PD, Burack JA. Deconstructing executive deficits among persons with autism: implications for cognitive neuroscience. Brain Cogn. 2007; 65:77-86. [PubMed: 17825970]

Sahyoun CP, Belliveau JW, Soulieres I, Schwartz S, Mody M. Neuroimaging of the functional and structural networks underlying visuospatial vs. linguistic reasoning in high-functioning autism. Neuropsychologia. 2010; 48:86-95. [PubMed: 19698726]

Saitoh O, Courchesne E, Egaas B, Lincoln AJ, Schreibman L. Cross-sectional area of the posterior hippocampus in autistic patients with cerebellar and corpus callosum abnormalities. Neurology. 1995; 45:317-324. [PubMed: 7854533]

Scherf KS, Luna B, Minshew N, Behrmann M. Location, location, location: alterations in the functional topography of face- but not object- or place-related cortex in adolescents with autism. Front. Hum. Neurosci. 2010; 4:26. [PubMed: 20631857]

Schultz RT, Gauthier I, Klin A, Fulbright RK, Anderson AW, Volkmar F, Skudlarski P, Lacadie C, Cohen DJ, Gore JC. Abnormal ventral temporal cortical activity during face discrimination among individuals with autism and Asperger syndrome. Arch. Gen. Psychiatry. 2000; 57:331340. [PubMed: 10768694]

Schumann CM, Hamstra J, Goodlin-Jones BL, Lotspeich LJ, Kwon H, Buonocore MH, Lammers CR, Reiss AL, Amaral DG. The amygdala is enlarged in children but not adolescents with autism; the hippocampus is enlarged at all ages. J. Neurosci. 2004; 24:6392-6401. [PubMed: 15254095]

Schumann CM, Barnes CC, Lord C, Courchesne E. Amygdala enlargement in toddlers with autism related to severity of social and communication impairments. Biol. Psychiatry. 2009; 66:942949. [PubMed: 19726029]

Sears LL, Vest C, Mohamed S, Bailey J, Ranson BJ, Piven J. An MRI study of the basal ganglia in autism. Prog. Neuropsychopharmacol. Biol. Psychiatry. 1999; 23:613-624. [PubMed: 10390720]

Silk TJ, Rinehart N, Bradshaw JL, Tonge B, Egan G, O'Boyle MW, Cunnington R. Visuospatial processing and the function of prefrontal-parietal networks in autism spectrum disorders: a functional MRI study. Am. J. Psychiatry. 2006; 163:1440-1443. [PubMed: 16877661]

Sparks BF, Friedman SD, Shaw DW, Aylward EH, Echelard D, Artru AA, Maravilla KR, Giedd JN, Munson J, Dawson G, Dager SR. Brain structural abnormalities in young children with autism spectrum disorder. Neurology. 2002; 59:184-192. [PubMed: 12136055]

Stanfield AC, McIntosh AM, Spencer MD, Philip R, Gaur S, Lawrie SM. Towards a neuroanatomy of autism: a systematic review and meta-analysis of structural magnetic resonance imaging studies. Eur. Psychiatry. 2008; 23:289-299. [PubMed: 17765485]

Taber KH, Pierpaoli C, Rose SE, Rugg-Gunn FJ, Chalk JB, Jones DK, Hurley RA. The future for diffusion tensor imaging in neuropsychiatry. J. Neuropsychiatry Clin. Neurosci. 2002; 14:1-5. [PubMed: 11884647]

Tepest R, Jacobi E, Gawronski A, Krug B, Moller-Hartmann W, Lehnhardt FG, Vogeley K. Corpus callosum size in adults with high-functioning autism and the relevance of gender. Psychiatry Res. 2010; 183:38-43. [PubMed: 20542669]

Tesink CM, Buitelaar JK, Petersson KM, van der Gaag RJ, Kan CC, Tendolkar I, Hagoort P. Neural correlates of pragmatic language comprehension in autism spectrum disorders. Brain. 2009; 132:1941-1952. [PubMed: 19423680] 
Thakkar KN, Polli FE, Joseph RM, Tuch DS, Hadjikhani N, Barton JJ, Manoach DS. Response monitoring, repetitive behaviour and anterior cingulate abnormalities in autism spectrum disorders (ASD). Brain. 2008; 131:2464-2478. [PubMed: 18550622]

Toal F, Daly EM, Page L, Deeley Q, Hallahan B, Bloemen O, Cutter WJ, Brammer MJ, Curran S, Robertson D, Murphy C, Murphy KC, Murphy DG. Clinical and anatomical heterogeneity in autistic spectrum disorder: a structural MRI study. Psychol. Med. 2010; 40:1171-1181. [PubMed: 19891805]

Tsatsanis KD, Rourke BP, Klin A, Volkmar FR, Cicchetti D, Schultz RT. Reduced thalamic volume in high-functioning individuals with autism. Biol. Psychiatry. 2003; 53:121-129. [PubMed: 12547467]

Turner KC, Frost L, Linsenbardt D, McIlroy JR, Muller RA. Atypically diffuse functional connectivity between caudate nuclei and cerebral cortex in autism. Behav. Brain Funct. 2006; 2:34. [PubMed: 17042953]

Uddin LQ, Menon V. The anterior insula in autism: under-connected and under-examined. Neurosci. Biobehav. Rev. 2009; 33:1198-1203. [PubMed: 19538989]

Vidal CN, Nicolson R, DeVito TJ, Hayashi KM, Geaga JA, Drost DJ, Williamson PC, Rajakumar N, Sui Y, Dutton RA, Toga AW, Thompson PM. Mapping corpus callosum deficits in autism: an index of aberrant cortical connectivity. Biol. Psychiatry. 2006; 60:218-225. [PubMed: 16460701]

Voelbel GT, Bates ME, Buckman JF, Pandina G, Hendren RL. Caudate nucleus volume and cognitive performance: are they related in childhood psychopathology? Biol. Psychiatry. 2006; 60:942950. [PubMed: 16950212]

Waiter GD, Williams JH, Murray AD, Gilchrist A, Perrett DI, Whiten A. A voxel-based investigation of brain structure in male adolescents with autistic spectrum disorder. Neuroimage. 2004; 22:619-625. [PubMed: 15193590]

Wang AT, Dapretto M, Hariri AR, Sigman M, Bookheimer SY. Neural correlates of facial affect processing in children and adolescents with autism spectrum disorder. J. Am. Acad. Child Adolesc. Psychiatry. 2004; 43:481-490. [PubMed: 15187809]

Wang AT, Lee SS, Sigman M, Dapretto M. Neural basis of irony comprehension in children with autism: the role of prosody and context. Brain. 2006; 129:932-943. [PubMed: 16481375]

Weeks SJ, Hobson RP. The salience of facial expression for autistic children. J. Child Psychol. Psychiatry. 1987; 28:137-151. [PubMed: 3558531]

Williams JH, Waiter GD, Gilchrist A, Perrett DI, Murray AD, Whiten A. Neural mechanisms of imitation and 'mirror neuron' functioning in autistic spectrum disorder. Neuropsychologia. 2006; 44:610-621. [PubMed: 16140346] 


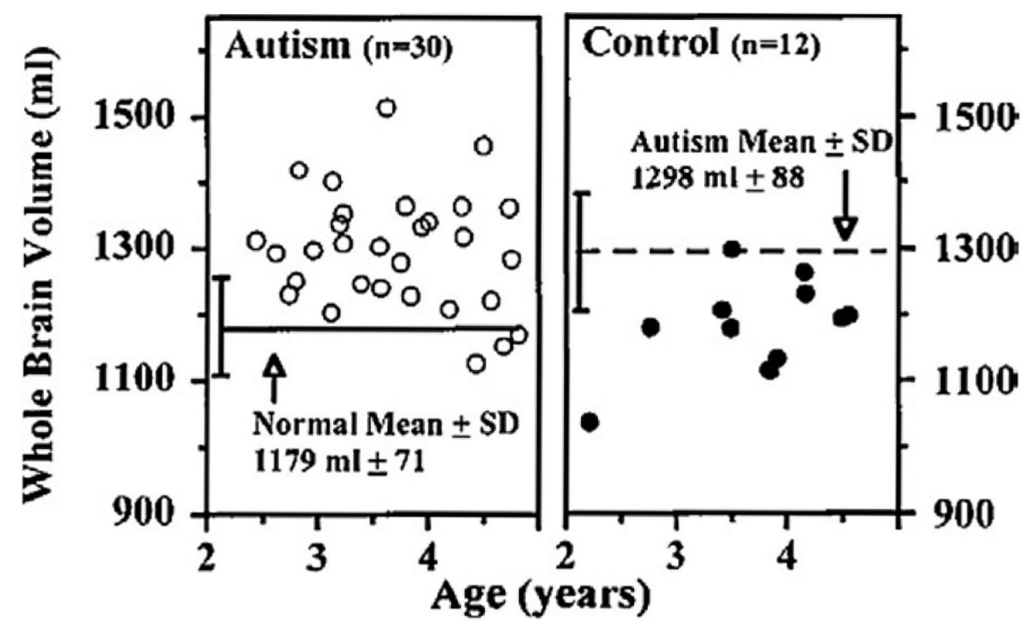

Fig. 1.

Whole brain volume by age. Two- to four-year-old autistic and normal boys are plotted showing overall whole brain enlargement of the youngest autistic children. As shown, $90 \%$ of the autistic boys had whole brain volumes larger than the normal mean. In contrast, only one normal boy in this age range exceeded the autism mean (from Courchesne et al., Neurology 2001). 


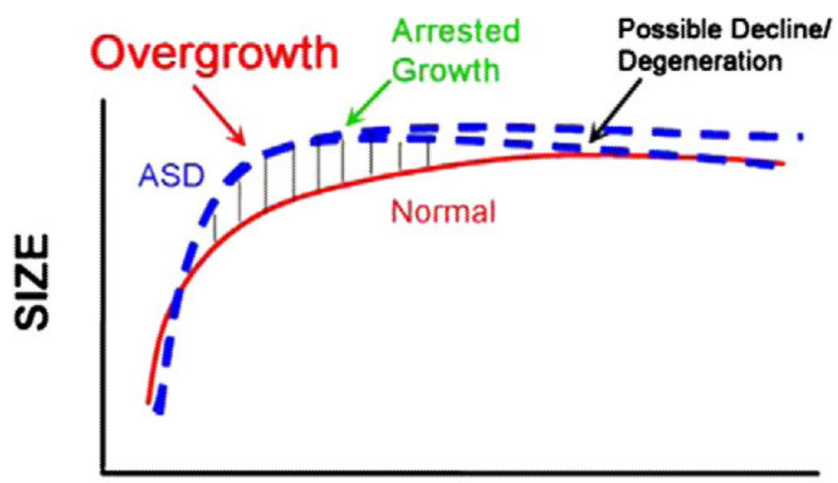

\section{AGE}

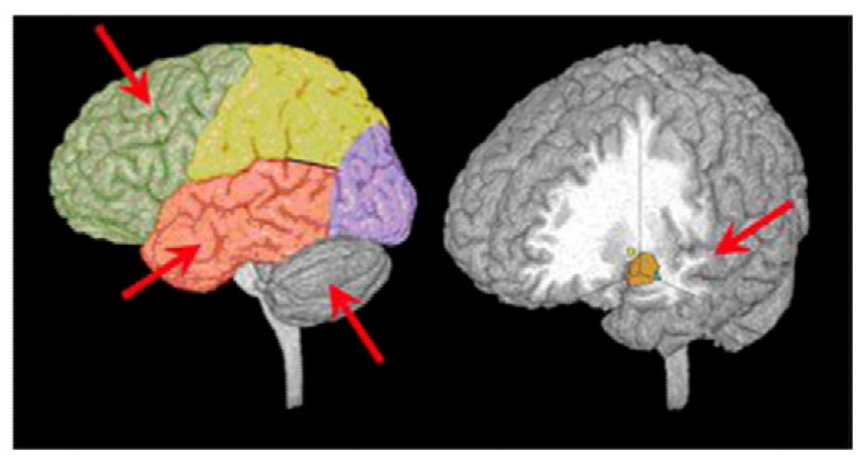

Fig. 2.

Regional early overgrowth in ASD. (Top) Model of early brain overgrowth that is followed by arrest of growth. Blue lines represent ASD, while red lines represent age matched typically-developing individuals. In some regions and individuals, the arrest of growth may be followed by degeneration, indicated by the blue dashes that slope slightly downward. (Bottom) Sites of regional overgrowth in ASD include frontal and temporal cortices, cerebellum, and amygdala (from Courchesne et al., Neuron 2004). 

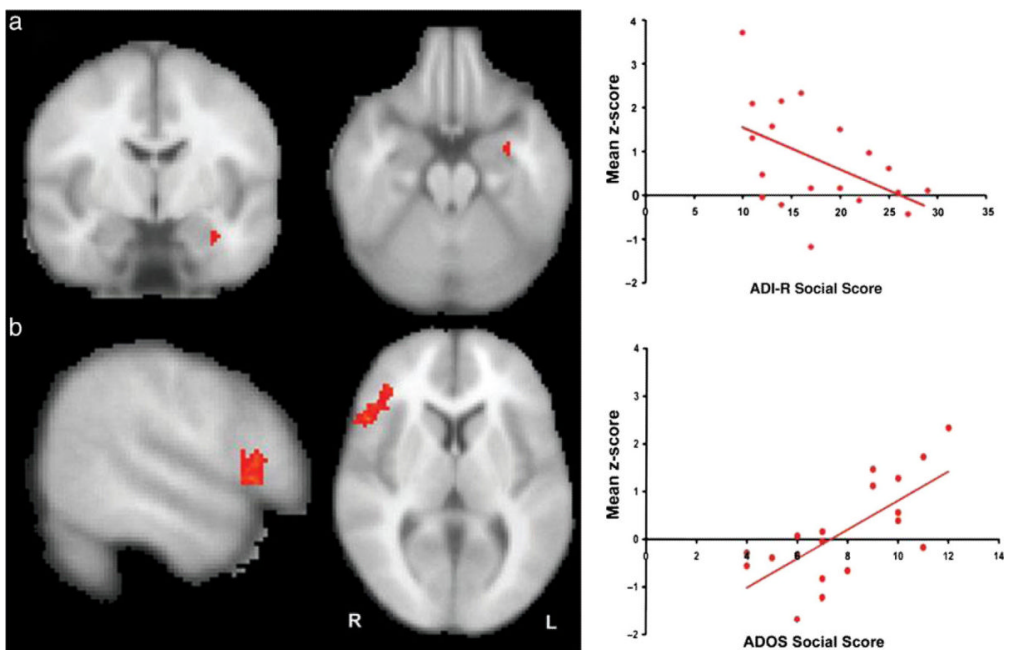

Fig. 3 .

Relationship between functional connectivity and clinical severity in the ASD group. (a) An inverse correlation between fusiform face area-left amygdala connectivity and the Autism Diagnostic Interview-Revised (ADI-R) social score was found. A scatter plot depicting the relationship between face-specific connectivity and social severity on the ADI-R is shown to the right of the functional activation map. The mean $\mathrm{z}$-score value for the amygdala was based on the average $\mathrm{z}$-score of the cluster showing a significant relationship between connectivity and ADI-R social score. (b) A direct relationship between autism diagnostic observation schedule (ADOS) social score and activation in the right inferior frontal gyrus was found in the ASD group. The individuals with ASD with the most severe level of current functioning as measured by the ADOS showed increased connectivity to the right inferior frontal gyrus during face processing. The scatter plot depicts the relationship between the face-specific functional connectivity activation and the ADOS. The mean zscore values for the right inferior frontal gyrus was based on the average z-score of the cluster showing a significant relationship between connectivity and the ADOS social score (from Kleinhans et al., Brain 2008b). 

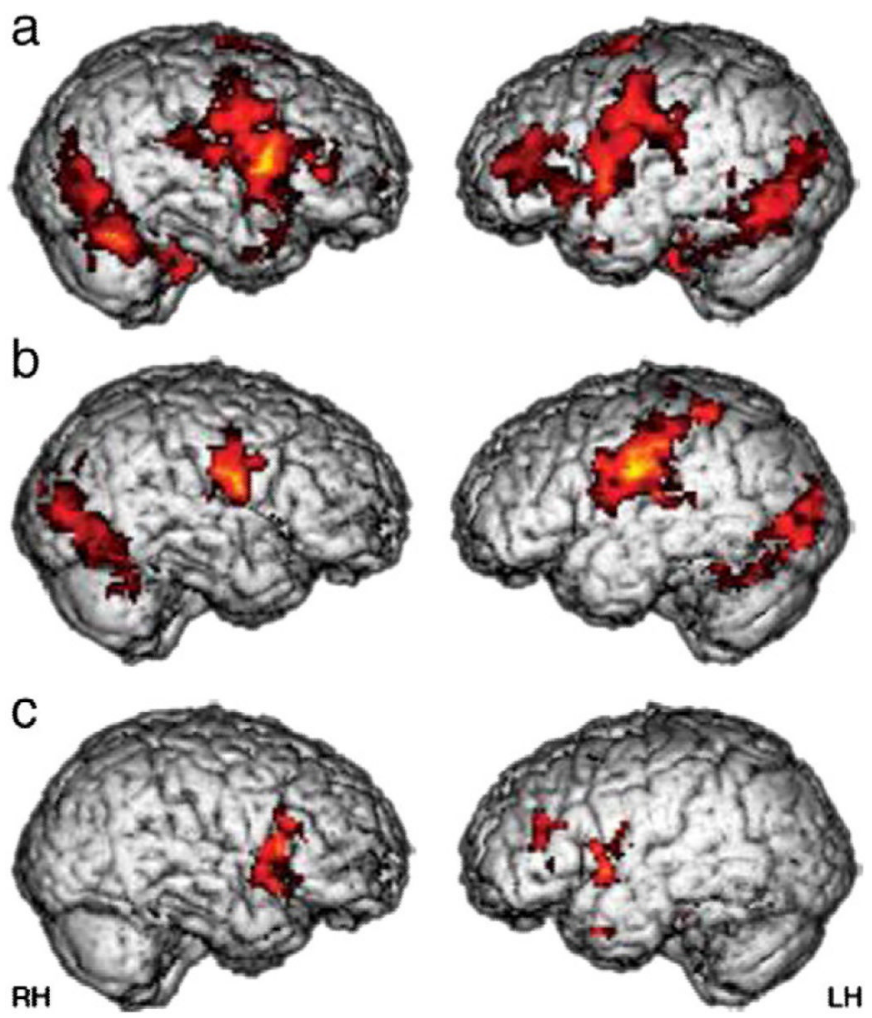

Fig. 4.

Reliable activity during imitation of emotional expressions: ( $a$ and b) Activity in bilateral pars opercularis (stronger in the right) of the inferior frontal gyrus is seen in the typicallydeveloping group (a) but not in the ASD group (b). A between-group comparison (c) revealed that this difference was significant $(\mathrm{t}>1.83, P<0.05$, corrected for multiple comparisons at the cluster level). (RH=right hemisphere; $\mathrm{LH}=$ left hemisphere) (from Dapretto et al., Nature Neuroscience 2006). 